\title{
Non-Pharmaceutical Techniques for Obstructive Airway Clearance Focusing on the Role of Oscillating Positive Expiratory Pressure (OPEP): A Narrative Review
}

Dominic P. Coppolo $\cdot$ Judy Schloss $\cdot$ Jason A. Suggett $\cdot$

Jolyon P. Mitchell (i)

Received: August 9, 2021 / Accepted: October 29, 2021 / Published online: December 3, 2021

(c) The Author(s) 2021

\section{ABSTRACT}

Mucus secretion in the lungs is a natural process that protects the airways from inhaled insoluble particle accumulation by capture and removal via the mucociliary escalator. Diseases such as cystic fibrosis (CF) and associated bronchiectasis, as well as chronic obstructive pulmonary disease (COPD), result in mucus layer thickening, associated with high viscosity in $\mathrm{CF}$, which can eventually lead to complete airway obstruction. These processes severely impair the delivery of inhaled medications to obstructed regions of the lungs, resulting in poorly controlled disease with associated increased mor-

D. P. Coppolo $\cdot$ J. Schloss

Monaghan Medical Corp, Plattsburgh, NY, USA

J. A. Suggett

Trudell Medical International, London, ON, Canada

J. P. Mitchell $(\bowtie)$

Jolyon Mitchell Inhaler Consulting Services Inc.,

1154 St. Anthony Road, London, ON N6H 2R1,

Canada

e-mail: mitchelljolyon@gmail.com bidity and mortality. This narrative review article focuses on the use of non-pharmacological airway clearance therapies (ACTs) that promote mechanical movement from the obstructed airway. Particular attention is given to the evolving application of oscillating positive expiratory pressure (OPEP) therapy via a variety of devices. Advice is provided as to the features that appear to be the most effective at mucus mobilization.

Keywords: Mucus clearance; Inhaled medication; Cystic fibrosis; Chronic obstructive pulmonary disease; Positive expiratory pressure; Oscillating positive expiratory pressure 


\section{Key Summary Points}

In addition to the potential for improving lung ventilation, quality of life, and exacerbation control, excess mucus removal has important benefits associated with the avoidance of opportunistic infection from pathogens.

Significant functional differences exist between oscillating positive expiratory pressure (OPEP) devices.

Observed variations in OPEP functional performance may alter therapeutic effectiveness making it difficult to translate improved patient outcomes between devices.

Traditional pulmonary function measures appear to be insensitive to various airway clearance techniques, including OPEP devices.

Radiolabeled imaging techniques reveal observable changes in airway patency and combined with real-world evidence, may provide more value in assessing device type in terms of ability to mobilize mucus plugs and thereby aid in improving therapeutic effectiveness.

\section{INTRODUCTION}

Mucus secretion is a natural process that protects the delicate alveolar gas-exchange region of the lungs from inhaled insoluble particle accumulation by capture and removal via the mucociliary escalator [1]. The presence of a thin mucus lining also defends the airways of lungs from pathogens seeking to target the cells lining the airways or using the lungs as a portal of entry to organs distal to the lungs via either the lymphatic and/or bloodstream routes [2]. A further function of mucus is to provide moisture to the epithelial lining [1]. Normal mucus is a low-viscosity fluid primarily comprised of

approximately $95 \%$ water. The other components include $2-3 \%$ glycoproteins (from goblet cells and submucosal glands), proteoglycans $(0.1-0.5 \%)$, lipids $(0.3-0.5 \%)$, proteins, and deoxyribonucleic acid (DNA) [3]. Under ordinary conditions, mucus is produced continuously from goblet cells lining the epithelium of the conducting airways. The projecting microscopic hair-like cilia $(6-7 \mu \mathrm{m}$ long and $0.2-0.3 \mu \mathrm{m}$ in diameter [4]), move mucus and incorporated debris up the respiratory escalator. The viscoelastic properties of the overlying mucus layer facilitate the transfer of energy from the cohesive beating cilia to mobilize the mucus layer $[5,6]$. This process ultimately transfers the mucus to the oropharynx via the carina, whereupon it is either swallowed or expectorated by coughing [2]. Effective mucus clearance is therefore essential for maintaining respiratory health [7].

Several acute and chronic respiratory diseases result in a large increase in mucus viscosity and/or rate of mucus production (hypersecretion) [8]. In cystic fibrosis (CF), the viscosity increase is brought about by dysregulation of the epithelial sodium channel, resulting in dehydration of airway surfaces [9]. The accumulation of over-abundant and highly viscous mucus that cannot be easily cleared via the mucociliary escalator results in plug formation, blocking gas exchange via the alveolar sacs served by that airway [10]. Mucus hypersecretion is also an important aspect of chronic obstructive pulmonary disease (COPD), resulting in effective airway narrowing leading to eventual blockage, an outcome that ultimately impairs lung function in association with episodes of severe acute exacerbations of disease [11]. The causes of excessive mucus production are more complex than in CF and have been attributed to increased secretion [12], decreased mucociliary clearance [7] and/or reduced mucin degradation within the airways [13]. In COPD, mucus viscosity is also increased, often by the action of agents in smoke inhalation associated with cigarette use as a cause of this deleterious change [14]. Bronchiectasis is a lung condition in which the airways become abnormally and permanently widened [15]. Neutrophil activity leads to hypersecretion and associated 
accumulation of excess mucus, resulting in an increased risk for patients to acquire opportunistic infections from inhaled pathogens [16]. The pathology of mucus hypersecretion is also complex in asthma. However, it is known that the mucin, MUC5AC, which is the principal gelforming mucin is upregulated in the airway inflammation that is characteristic of this condition [17].

In summary, excessive mucus accumulation in the airways of the lungs associated with various chronic diseases is associated with changes in rheological properties, principally an increase in viscosity, which leads to mucociliary escalator malfunction. Combined with inefficient expectoration, these processes are the precursor to inflammation and infection, airway obstruction and parenchyma damage (Fig. 1) [18].

It is self-evident from the foregoing that mucus mobilization and elimination from the lungs, either by expectoration or swallowing, are highly desirable therapeutic goals. As a result, many different therapeutic strategies have been developed to address this issue. These approaches can be summarized as falling into two broad categories, inhaled therapies, and physical aids (Fig. 2). Inhaled pharmacologic therapies are largely based on expectorants, such as hypertonic saline, mucolytic agents such as $\mathrm{N}$-acetylcysteine and anticholinergic muco-regulatory medications [19], and are outside the scope of this article. Physical methodologies can be further sub-divided into assisted chest therapies/airway clearance techniques (ACTs), specialized breathing techniques, such as the 'huff-cough' maneuver, and mechanical mobilization methods [6].

The purpose of this review is to provide clinicians with sufficient information to enable them to judge the features, advantages and disadvantages of the wide variety of mechanical mobilization techniques currently available primarily in North America, focusing on OPEP devices. In the past ten years, significant advances have been made in the development of these small, low cost, and portable devices for patients to administer therapy either under the supervision of a clinical professional, or by themselves on an 'as-needed' basis [20]. These advances have been accompanied by research that has improved the understanding of how these therapies function to optimize device performance [21]. This article is based on previously conducted studies and does not contain any new studies with human participants or animals performed by any of the authors.

\section{MECHANICAL MUCUS MOBILIZATION TECHNIQUES}

\section{Function and Relationship with Manual Methods}

The mechanisms of action on mucus clearance applied either externally to the patient or internally are still unclear. However, it is widely understood that the imparted forces from such therapies may reduce the viscoelasticity of the secretions [22]. The basic function of mechanical methods is to impart sufficient external kinetic energy, with or without the assistance of the patient via coughing, to displace the accumulated mucus layer towards the upper respiratory tract for consequent expectoration or swallowing and digestion [23]. ACTs augment a series of treatments in which mucus is mobilized manually either by a caregiver, including postural drainage, clapping and vibration, highfrequency chest wall compression, or directly by the patient, using techniques such as self (autogenic drainage) and active cycle of breathing [24]. However, major drawbacks with these caregiver- or self-administered methods are the reliance on a secondary caregiver where needed to provide the therapy, patient discomfort and the lengthy time required per day to deliver effectively. Associated patient-driven procedures for mucus clearance take time to learn and, more importantly, may be difficult to perform during exacerbations [18].

\section{Mechanical Mucus Mobilization Therapies Other than OPEP}

The most widely encountered electro-mechanical mucus mobilization methods are summarized in Table 1. All treatments to a greater or lesser extent have been shown to provide 


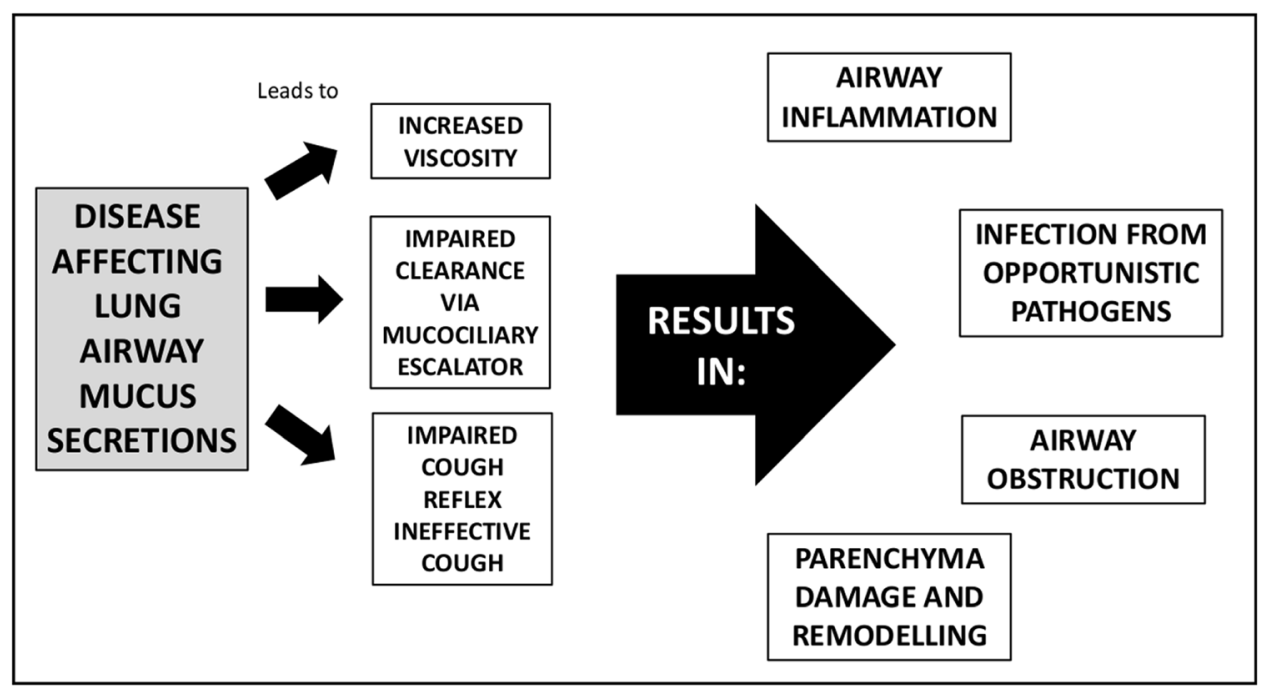

Fig. 1 Processes associated with mucus accumulation in the airways of the lungs and their consequences

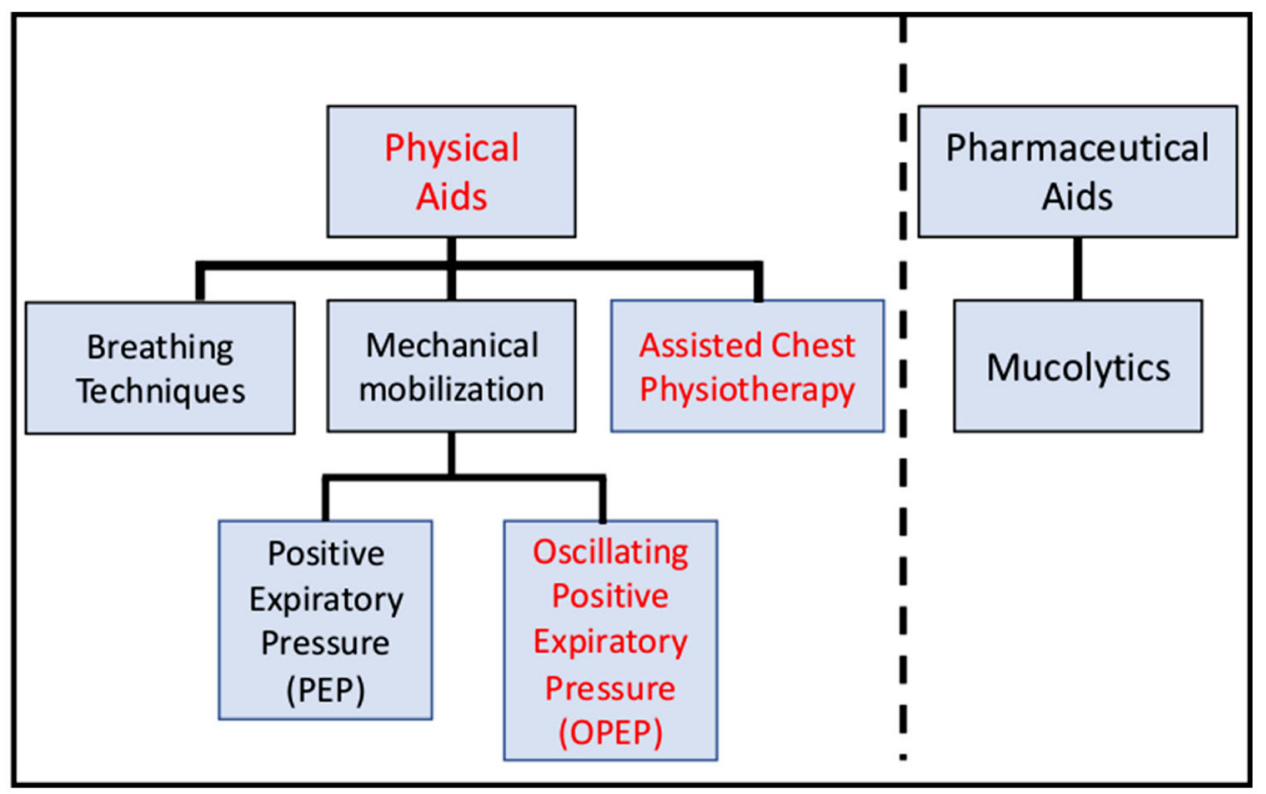

Fig. 2 The major therapeutic approaches for mucus mobilization from the airways of the lungs, showing the relationships between them

benefit in terms of increasing sputum production in patients with either COPD or CF [20]. However, the quality of the evidence comparing treatment modalities against recognized markers of improved pulmonary function, such as forced expiratory volume in $1 \mathrm{~s}\left(F E V_{1}\right)$, forced vital capacity $(F V C)$ and forced expiratory flow between $25 \%$ and $75 \%$ of $\mathrm{FVC}\left(F E F_{25-75 \%}\right)$ is hindered by a lack of sufficiently powered, longterm, randomized controlled trials [25].

\section{Mechanical Insufflation-Exsufflation (MI-E)}

Devices that apply mechanical MI-E function by gradually applying positive air pressure (insufflation) to the patient via a facemask to obtain a large volume of air within the lungs. The 
Table 1 Mechanical methods for airway mucus mobilization

\begin{tabular}{|c|c|c|}
\hline Procedure & Function & Mode of operation \\
\hline $\begin{array}{l}\text { Mechanical } \\
\text { Insufflation- } \\
\text { Exsufflation (MI- } \\
\text { E) }\end{array}$ & $\begin{array}{l}\text { Device is used with spontaneously breathing patients } \\
\text { to increase inspiratory lung volumes and peak } \\
\text { expiratory cough flow beyond the capability of the } \\
\text { patient }\end{array}$ & $\begin{array}{l}\text { 1: Filtered air is blown to the patient using } \\
\text { facemask, gradually applying positive } \\
\text { pressure } \\
\text { 2: Rapid shift to negative pressure follows to } \\
\text { suction mucus by stimulating cough } \\
\text { 3: Controlled pause duration before repeating } \\
\text { maneuver }\end{array}$ \\
\hline $\begin{array}{l}\text { Intrapulmonary } \\
\text { Percussive } \\
\text { Ventilation } \\
\text { (IPV) }\end{array}$ & $\begin{array}{l}\text { Device is used in pressure- or volume-controlled } \\
\text { mode with patients usually on mechanical } \\
\text { ventilation to open the airways }\end{array}$ & $\begin{array}{l}\text { Small (sub-physiologic tidal volume), high- } \\
\text { velocity bursts of air are sent from the IPV } \\
\text { device to the patient. These air pulses also } \\
\text { loosen and free mucus from airway walls }\end{array}$ \\
\hline $\begin{array}{l}\text { Chest Percussive } \\
\text { Clearance } \\
\text { Therapies (PCT) }\end{array}$ & $\begin{array}{l}\text { In air pulse-driven PCT, the patient wears an } \\
\text { inflatable vest that is attached to an air-pulse } \\
\text { generator that causes the vest to inflate and deflate } \\
\text { as rapidly as } 20 \mathrm{~Hz} \\
\text { In acoustic PCT, a series of acoustic pressure pulses } \\
\text { are applied externally to the airways. The energy } \\
\text { imparted to the mucus lining the airways applies } \\
\text { continuous stress through the generation of } \\
\text { acoustical (pressure) waves }\end{array}$ & $\begin{array}{l}\text { Typically, the user operates the vest for } 5 \mathrm{~min} \\
\text { and then coughs or huff-coughs to } \\
\text { expectorate mucus. Sessions last between } 20 \\
\text { and } 30 \text { min } \\
\text { The user adjusts the frequency of the } \\
\text { transducer (typically between } 25 \text { and } \\
40 \mathrm{~Hz} \text { ) such that a sympathetic resonance } \\
\text { occurs that is sensed by the patient in the } \\
\text { thoracic cavity. If successful, the application } \\
\text { of acoustic percussion induces coughing and } \\
\text { expectoration }\end{array}$ \\
\hline $\begin{array}{l}\text { Positive Expiratory } \\
\text { Pressure Therapy } \\
\text { (PEP) }\end{array}$ & $\begin{array}{l}\text { A fixed resistance to expiration is applied at the } \\
\text { mouth during exhalation via a facemask, and the } \\
\text { induced PEP maintains the airways open during } \\
\text { exhalation, helping to mobilize mucus secretions }\end{array}$ & $\begin{array}{l}\text { 1: Low PEP involves tidal volume inhalation } \\
\text { and exhalation against resistances that } \\
\text { produce pressures at the mouth of } 10 \text { to } \\
20 \mathrm{~cm} \mathrm{H}_{2} \mathrm{O}(980 \text { to } 1960 \mathrm{~Pa} \text { ) during } \\
\text { exhalation } \\
\text { 2: High PEP uses inhalations to recruit high } \\
\text { lung volumes and forced exhalations against } \\
\text { resistances that generate pressures greater } \\
\text { than } 20 \mathrm{~cm} \mathrm{H}_{2} \mathrm{O}(1960 \mathrm{~Pa}) \text { during } \\
\text { exhalation }\end{array}$ \\
\hline
\end{tabular}


Table 1 continued

\begin{tabular}{lll}
\hline Procedure & Function & Mode of operation \\
\hline $\begin{array}{l}\text { Oscillating PEP } \\
\text { Therapy (OPEP) }\end{array}$ & $\begin{array}{c}\text { OPEP devices generate intra-thoracic pressure } \\
\text { oscillations via the mouth during exhalation. } \\
\text { Variable resistance is created within the airways, } \\
\text { generating controlled oscillating positive pressure } \\
\text { which mobilizes mucus }\end{array}$ & $\begin{array}{l}\text { Various devices are available with slightly } \\
\text { different operating modalities. The patient } \\
\text { exhales against a continuously varying } \\
\text { resistance whose magnitude can be pre-set. }\end{array}$ \\
& $\begin{array}{l}\text { The pressure range is typically between } \\
10-20 \mathrm{~cm} \mathrm{H}_{2} \mathrm{O}(980 \text { to } 1960 \mathrm{~Pa}) \text {, at a flow }\end{array}$ \\
& $\begin{array}{l}\text { rate of } 10-201 / \text { min. The duration of } \\
\text { exhalation, not including breath-hold, is }\end{array}$ \\
& $3-4$ times the length of inhalation \\
\hline
\end{tabular}

resulting high expiratory flow helps mobilize secretions out of the airway, mimicking a deep, natural cough [26]. Subsequently, the air flow is rapidly reversed by shifting to negative air pressure to begin exsufflation, thereby mobilizing mucus secretions. One example is the CoughAssist* T70 airway clearance device (Philips, USA: https://www.usa.philips.com/ healthcare/product/HC0066000/coughassistt70-airway-clearance-device) that can be operated manually, in automatic mode in which a timing feature automatically triggers to inspiration and cycles to expiration, and in advanced automatic mode that allows the therapist to set a number of successive insufflations prior to the initiation of cough therapy. Great skill and care are needed to set and maintain the correct timing of each phase to suit the need of the patient [27]. The cost of MI-E machines may make them unaffordable for some individual users in the home setting, although likely within the range of many hospital department budgets, particularly in developed countries. Nevertheless, MI-E therapy may be appropriate when conventional cough assistance techniques become ineffective, such as for patients with advanced neuromuscular disease affecting respiration [26].

\section{Intrapulmonary Percussive Ventilation (IPV)}

IPV can be used either as a single treatment via facemask or mouthpiece to spontaneously breathing patients [28, 29] or via artificial airway as an adjunct therapy for patients undergoing mechanical ventilation [30, 31]. An example IPV device is the Impulsator* (Percussionaire ${ }^{\circledR}$, https://percussionaire.com/). The air pulses delivered to the patient provide mechanical force to loosen and free mucus from the airway walls. Small, high-velocity bursts of air are sent from this device to open the airways after setting the percussion frequency and the driving pressure [28]. Changing the driving pressure from 1.2 to 1.8 bar (120 to $180 \mathrm{kPa}$ ) increases the airways pressure generated during each percussion, where a decrease in frequency increases the volume of air delivered during each pulsation and may be better tolerated [28]. IPV is typically interspersed with periods of normal respiration. The cost of IPV devices is comparable with that for MI-E systems, again potentially making them beyond the financial reach of some patients, although likely accessible for hospital use.

\section{Air Pulse-Driven and Acoustic Pulmonary Clearance Therapies (PCTs)}

Both air pulse-driven and acoustic PCTs apply pulsating energy externally to the lungs. The energy imparted to the mucus lining the airways exerts continuous shear stress that serves to mobilize these secretions towards the oropharynx. In air pulse-driven PCT, termed high-frequency chest wall oscillation (HFCWO) therapy, the patient wears an inflatable vest that is attached to an air-pulse generator that causes 
the vest to inflate and deflate as rapidly as $25 \mathrm{~Hz}$ [32]. HFCWO, delivered via a percussive vest, is a commonly accepted means in North America for airway clearance CF and non-CF bronchiectasis [33]. The Vest ${ }^{\circledR}$ (Hilrom, https://www. hillrom.com/en/products/the-vest-system-105/) and Smartvest ${ }^{\circledR}$ (Electromed, https://smartvest. $\mathrm{com} /$ ) are two devices used to deliver this therapy. Patients typically operate the vest for $5 \mathrm{~min}$ at each setting and then they cough or huffcough in between adjustments to the settings to expectorate mucus. Sessions last between 20 and $30 \mathrm{~min}$. Acoustic Percussive Clearance Therapy (APCT) applies low-frequency sound waves to the chest of the patient. The Frequencer ${ }^{\circledR}$ (Dymedso Inc., https://www. dymedso.com/frequencer/) systems [34] are also an example of this class of aids. These devices operate by inducing oscillatory sound (pressure) waves in the chest by means of a large electro-acoustical transducer that is located on the patient's chest. APCT is delivered as a 'whole chest' resonance therapy rather than being localized to focus on regions of the lungs, although selective use of frequencies between 20 and $65 \mathrm{~Hz}$ can stimulate different resonances [35]. Versions are available either for single patient use or in multi-patient settings. Adherence with this form of therapy may, however, be a limitation, especially in pediatric use. For example, Benoit et al. in an adherence study with 62 children with CF aged from 2 to 19 years and treated with VEST*-delivered HFCWO therapy, reported that adherence in a week-long protocol was as low as about 30\% for the 25 enrolled adolescents aged 13-19 years, in terms of retention of the clinician-set oscillation frequencies and pressures [36]. The cost of devices in this acoustic PCT class is comparable with that for MI-E machines.

\section{Positive Expiratory Pressure (PEP) Therapy}

PEP therapy involves exhaling against a fixed resistance via either a mouthpiece or facemask. There are several ways of administering PEP, the simplest of which uses a flow resistor such as a small diameter orifice located in the exhalation flow pathway [37]. At a given flow rate, resistance increases as orifice diameter decreases. Figure 3 illustrates a generic PEP device with the different patient interfaces and shows the oneway valve that opens during inhalation but closes at onset of exhalation, diverting the flow from the patient via the resistor. The Portex* Thera-PEP* device (Smiths Medical, https:// www.smiths-medical.com/en-ca/products/ respiratory/bronchial-hygiene/therapep-peptherapy-system) is an example of a device that delivers straightforward PEP therapy without oscillations with six user-selectable exhalation flow resistance settings. Other ways to generate PEP utilize a spring or magnet threshold resistor, which allows flow only when PEP reaches the requisite pre-set threshold level. This

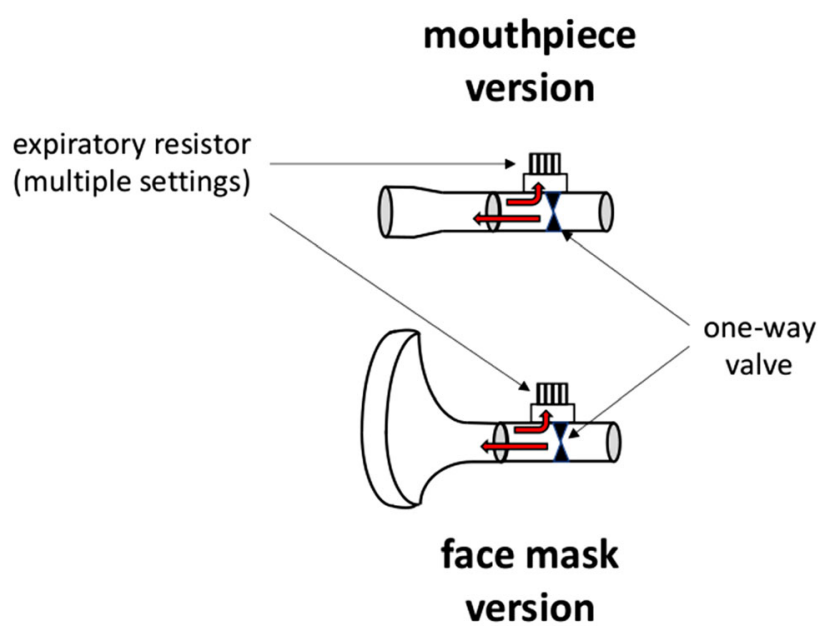

Fig. 3 Generic PEP therapy device showing mouthpiece and facemask patient interface alternatives 
enhancement allows for calibration of the obstructing force mechanism to ensure the desired PEP level is achieved and avoids the need for a pressure-monitoring device [37]. The Threshhold* $^{*}$ PEP device (Philips, https://www. usa.philips.com/healthcare/product/

HCHS735010/treshold-positive-expiratory-

pressure-device) is an example of a device delivering this therapy. A third method employs an external flow source to oppose the expiratory flow and thus generate PEP [37]. There are also combination PEP devices that make use of threshold resistance together with opposing flow. This modality is employed in the VersaPAP* Positive Airway Pressure (PAP) device (Monaghan Medical Inc., https://www. monaghanmed.com/versapap/). The addition of auxiliary flow allows for positive airway pressure generation on both the inspiratory and expiratory phases of the breathing cycle. The VersaPAP* aid has an integrated manometer that provides immediate feedback, making it easy to monitor and achieve a wide range of desired airway pressures in the range from 6 to $32 \mathrm{~cm} \mathrm{H}_{2} \mathrm{O}$ (590 to $3140 \mathrm{~Pa}$ ). PAP has been shown to help reduce or reverse atelectasis [38]. The incorporation of a manometer in such devices is an important feature, since Christensen et al., have identified that it is difficult to both teach and acquire the optimal technique in terms of imparting and learning, respectively, how fast and how much to exhale. A manometer enables standardization of the exhalation maneuver [39]. Such pressure-regulated devices have a targeted pressure that must be achieved before expiratory flow can start [39].

In a typical regimen using a flow resistorbased PEP device as an example [40], the patient breathes tidally, with a slightly active expiration through the expiratory resistor that produces expiratory pressures often between 10 and $20 \mathrm{~cm} \mathrm{H}_{2} \mathrm{O}$ (980 to $1960 \mathrm{~Pa}$ ) at mid-expiration. The patient then removes the mouthpiece or facemask and undertakes two to three forced expirations followed by a cough to clear mobilized secretions (huff-cough maneuver). This procedure is proceeded by a 1-2-min period of relaxed, controlled breathing. The complete sequence is then repeated six times, requiring about $20 \mathrm{~min}$ to complete. The entire process is undertaken twice daily. The purpose of PEP is to stent airways open or increase intrathoracic pressure distal to retained secretions by increasing functional residual capacity (FRC) [41] and/or collateral ventilation channels [42]. In short-term studies, PEP has been observed to be at least as effective as the traditional postural drainage and percussion therapy used to mobilize mucus secretions in patients with $\mathrm{CF}$ [43-45]. in a long-tern investigation lasting $1 \mathrm{y}$ on each of these regimens, PEP has also been shown to be superior in maintaining pulmonary function [46]. However, McIlwaine et al. [47] have cautioned that the most effective technique for secretion clearance during an infective exacerbation of CF may differ from that which is most effective for maintenance therapy. The chosen PEP technique is therefore ideally also used in combination with various other interventions (e.g., pharmacological therapies, other physical therapy, or ACTs). In summary, McIlwaine et al. [47] concluded that there is some evidence to recommend PEP as a more acceptable intervention long term than other forms of physiotherapy. Further, they suggested that PEP delivery by facemask should be given early consideration, especially if patients experience a higher than usual/expected exacerbation rate.

In contrast with the other forms of mechanical mobilization methods previously described, the cost of a typical PEP device is much lower, often $<\$ 100$. Therapy can be selfadministered in the domiciliary setting as well as at a hospital.

\section{OPEP THERAPY}

\section{Principle of Operation}

OPEP therapy devices are an extension of fixed PEP treatment and have become increasingly widespread in the past 20-25 years [41, 48, 49]. They function by a variety of mechanisms that create a series of short duration occlusions of flow when the patient exhales into the device [42]. A series of oscillatory airway pressure changes is generated as the patient inhales a 


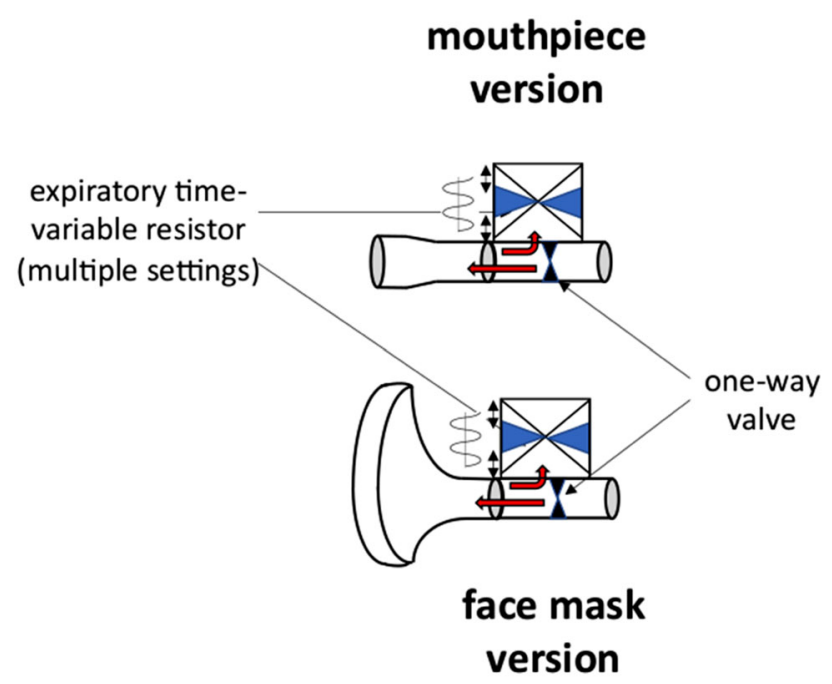

Fig. 4 Generic OPEP therapy device showing mouthpiece and facemask patient interface alternatives
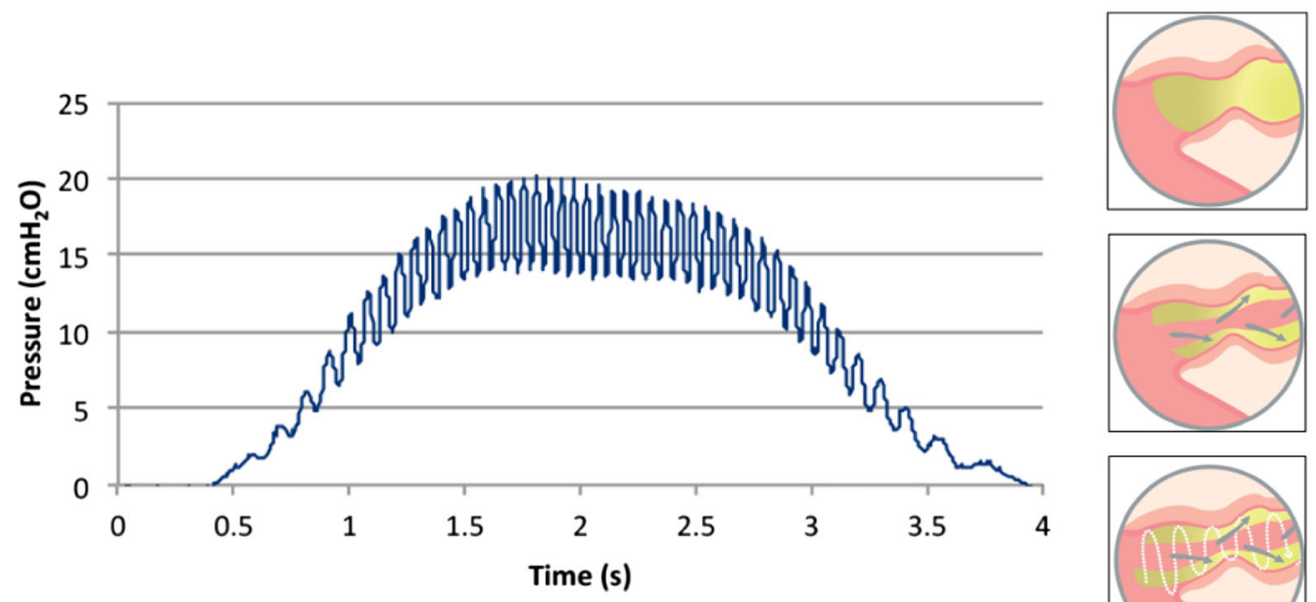

Airway with a mucus plug

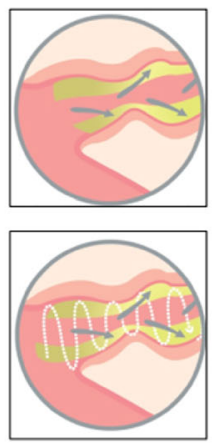

Resistance holds the airways open

Pulses help thin and loosen mucus while the airways are held open

Fig. 5 Oscillatory pressure train developed by exhaling into an OPEP device; the baseline positive pressure stents the large airways whilst the oscillations mobilize the excessive mucus secretions lining the airways

slightly larger-than-normal tidal volume and actively exhales through the device [50]. These pressure fluctuations result in corresponding variations in the exhaled flow rate-time waveform profile [42]. The oscillation frequency and amplitude can be adjusted to some extent with many of the devices currently available [37]. These oscillations create shear forces that reduce the viscoelasticity of bronchial secretions [41, 51], facilitating mucus mobilization $[52,53]$.

Figure 4 depicts a generic OPEP device showing both mouthpiece and facemask patient interface options. In use, the patient exhales through the device opening the one-way valve creating intermittent resistance that results in positive pressure and oscillations simultaneously [43]. Positive pressure acts to stent the airways and the oscillations help thin and 
Table 2 Commonly prescribed hand-held OPEP devices: (adapted and updated from Demchuk and Chatburn [37])

\begin{tabular}{|c|c|c|c|c|}
\hline $\begin{array}{l}\text { Device } \\
\text { name }\end{array}$ & Manufacturer & $\begin{array}{l}\text { Operating } \\
\text { principle }\end{array}$ & OPEP settings & $\begin{array}{l}\text { FDA } \\
510(k) \text { number }\end{array}$ \\
\hline Aerobika* & $\mathrm{TMI}^{1} / \mathrm{MMC}^{2}$ & Mechanical & $\begin{array}{l}\text { Intermittent occlusion with } 5 \text { resistance settings, to vary } \\
\text { pressure at constant flow, using an external lever }\end{array}$ & $\begin{array}{l}\text { K123400 } \\
\text { K150173 }\end{array}$ \\
\hline Acapella* & $\begin{array}{l}\text { Smiths } \\
\text { Medical }\end{array}$ & Mechanical & $\begin{array}{l}\text { Intermittent occlusion: original blue model for pediatric use } \\
\text { (max flow rate } 15 \mathrm{l} / \mathrm{min} \text { ) produces a lower amplitude of } \\
\text { vibrations compared to Green or Choice models; new } \\
\text { blue Choice model has same minimum flow rate ( } 15 \\
1 / \mathrm{min} \text { ) as green model }\end{array}$ & $\begin{array}{l}\text { K002768 } \\
\text { K181660 (new } \\
\text { blue) }\end{array}$ \\
\hline Flutter* & Allergan Inc & Mechanical & $\begin{array}{l}\text { Resistance varied by adjusting angle of tilt of device from } 0^{\circ} \\
\text { (low) to } 20^{\circ} \text { (medium) to } 40^{\circ} \text { (high). Cannot be used in- } \\
\text { line with a nebulizer }\end{array}$ & $\begin{array}{l}\text { K946083, } \\
\text { K940986, } \\
\text { K972859 }\end{array}$ \\
\hline Lung Flute* & $\begin{array}{l}\text { Medical } \\
\text { Acoustics } \\
\text { LLC }\end{array}$ & Acoustic & $\begin{array}{l}\text { Fixed resistance - forceful exhalation generates a sound } \\
\text { (pressure) wave of intensity from } 110 \text { to } 115 \mathrm{~dB}\end{array}$ & $\begin{array}{l}\text { K091557, } \\
\text { K060439 }\end{array}$ \\
\hline PocketPEP* & $\begin{array}{l}\text { DR Burton/ } \\
\text { Vyaire }\end{array}$ & Mechanical & Device operates by intermittent occlusion & K160636 \\
\hline Quake* $^{*}$ & $\begin{array}{l}\text { Thayer } \\
\text { Medical }\end{array}$ & Mechanical & $\begin{array}{l}\text { External handle enables rotation of inner with respect to } \\
\text { outer barrel of device - degree of misalignment of } \\
\text { matching slots in each barrel creates increased resistance }\end{array}$ & K974849 \\
\hline $\begin{array}{l}\text { RC- } \\
\text { Cornet }\end{array}$ & $\begin{array}{l}\text { Cegla, } \\
\text { Germany }\end{array}$ & Mechanical & $\begin{array}{l}4 \text { resistance settings by rotating device body against adapter. } \\
\text { A valved ' } T \text { '-adapter is required for use with a nebulizer }\end{array}$ & K983308 \\
\hline ShurClear* & $\begin{array}{l}\text { Mercury } \\
\text { Medical Inc }\end{array}$ & Mechanical & $\begin{array}{l}\text { Intermittent fixed occlusion with variable oscillation } \\
\text { frequency by tilting device }\end{array}$ & K121587 \\
\hline Vibralung* & Westmed Inc & Acoustic & Transducer creates sound waves at different frequencies & K133057 \\
\hline vPEP* & $\begin{array}{l}\text { DR Burton/ } \\
\text { Vyaire }\end{array}$ & Mechanical & Intermittent occlusion with adjustable resistance settings & K160636 \\
\hline Vibra-PEP* & $\begin{array}{l}\text { Medica } \\
\text { Holdings }\end{array}$ & Mechanical & $\begin{array}{l}\text { Intermittent occlusion with } 5 \text { resistance settings. Cannot be } \\
\text { used with a nebulizer }\end{array}$ & K163091 \\
\hline
\end{tabular}

${ }^{1}$ Trudell Medical International-Canada

${ }^{2}$ Monaghan Medical Corporation-USA

loosen adherent mucus from the airway lumen [43], as illustrated by the cartoons on the righthand of Fig. 5. Ideally, the frequency of oscillation is matched to the ciliary beat frequency from 11 to $15 \mathrm{~Hz}$ [54-56]. Most OPEP devices have a means to alter the expiratory flow resistance [44]. However, increasing resistance will likely decrease the maximum expiratory flowrate achieved, especially with COPD patients [57]. The combination of applied airway pressure changes associated with the oscillations helps move the mucus plugs towards the 

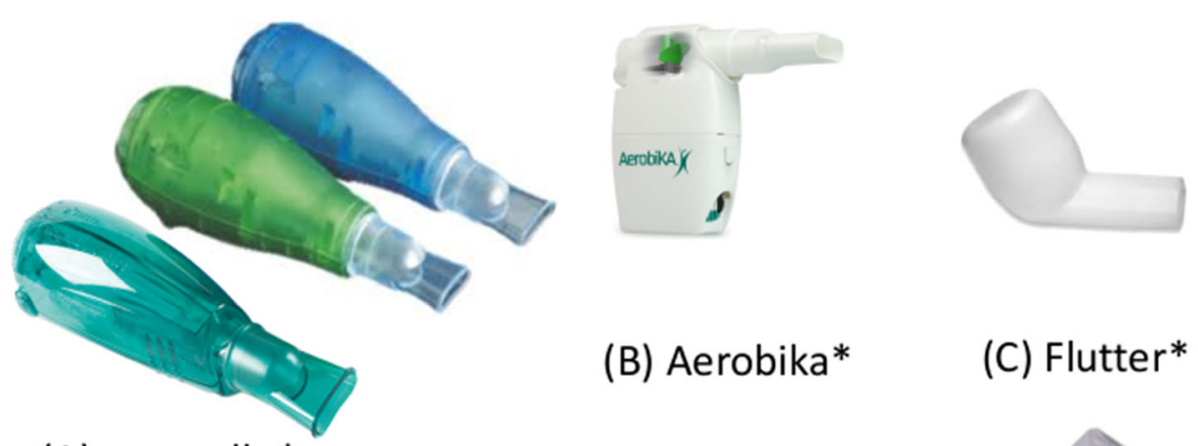

(B) Aerobika*

(C) Flutter*

(A): acapella* green and blue versions

With acapella*
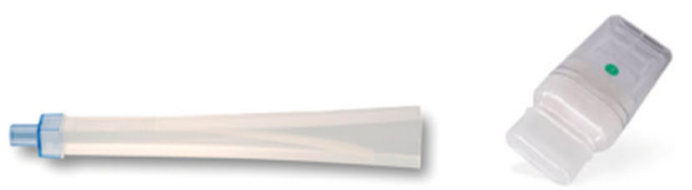

Choice $\ddagger$ green below

(D) Lung Flute*

(E) PocketPep*

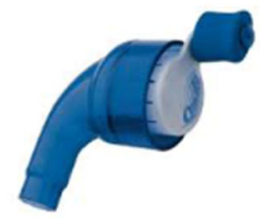

(F) Quake*

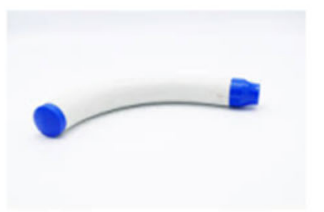

(G) RC-Cornet*

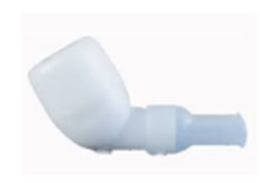

(H) ShurClear*

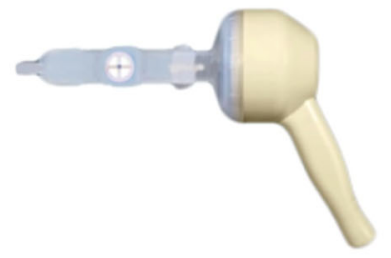

(I) Vibralung*

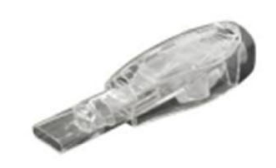

(J) VPEP*

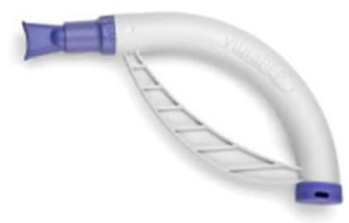

(K) VibraPEP*

Fig. 6 A selection of the commonly encountered OPEP devices in North America and Europe

central and upper airways where they can be expectorated. Secretion removal is then also encouraged either by the patient forcing deep exhalations through the device or with subsequent huff/coughing [41]. There are several different OPEP devices available (Table 2), and a selection of devices encountered in North America and Europe is illustrated in Fig. 6, based on their appearance in previous literature reviews $[37,40,41,54,58,59]$ and proprietary market knowledge of the authors. Their individual properties are described in the next section. They are all portable and low cost compared with appliances for delivery of MI-E, IPV and HFCWO, and therefore more readily available for patients to self-administer therapy normally under the guidance of a clinician. Ultimately, patients have the choice of using a handheld OPEP device on its own or in combination/adjunct with one of these more expensive ACT options. 


\section{OPEP Devices (in Alphabetical Order)}

Most of the information in this section, which is not an exhaustive list, but which illustrates the principal methods used to generate OPEP, is based on a recent comparative assessment of devices available in North America by Demchuk and Chatburn [37]. We have also indicated other sources where appropriate.

\section{Acapella* (Smiths Medical/Carefusion)}

There are currently several versions of the Acapella* OPEP device that may be encountered: (https://www.smiths-medical.com/en-ca/ products/respiratory/bronchial-hygiene/ acapella-vibratory-pep-therapy-system-visited October 4 2021). Each version is approximately $17 \mathrm{~cm}$ in length by $10 \mathrm{~cm}$ deep and $10 \mathrm{~cm}$ wide, and therefore larger than most other OPEP devices (Fig. 6a). They function by means of a counterweighted plug and short metal strip attached to a lever and a magnet. Oscillating airflow is initiated on exhalation through the patient interface by the breaking and reforming of the magnetic field, thereby intermittently occluding the passing air flow. The expiratory resistance and oscillation profile can be adjusted by means of an adjustable dial that changes the distance between the magnet and the metal strip.

The green version of the Acapella* series (Acapella* DH) is intended for patients whose sustained expiratory flow rate exceeds $15 \mathrm{l} / \mathrm{min}$. The original blue version (Acapella* DM) was generally intended for individuals with an expiratory flow rate less than this limit, because it produced a lower amplitude of vibrations compared to the other devices of this design [60]. In 2003, Volsko et al. observed that the original blue version may be more useful than other Acapella* devices available at that time, as it can be applied in those having severe airflow obstruction, and/or airway instability [58].

The teal-colored Acapella* Choice* device (https://www.smiths-medical.com/en-ca/ products/respiratory/bronchial-hygiene/ acapella-choice-vibratory-pep-therapy-systemvisited Oct 4 2021) is also intended for those capable of exhaling with a flow-time profile exceeding $15 \mathrm{l} / \mathrm{min}$, but unlike the original blue and green versions, it can be taken apart into four components (cover, mouthpiece, base and rocker assembly (the latter as a single unit not further separatable)) to be cleaned between uses. In 2021, a new version of the blue Acapella* device became available with a similar design to the Choice* option, enabling disassembly for cleaning. The minimum flow rate for this new device is now specified as being 15 $1 /$ min (Table 2).

Finally, the clear Acapella* Duet $^{*}$ option (https://www.smiths-medical.com/en-ca/ products/respiratory/bronchial-hygiene/ acapella-duet-vibratory-pep-therapy-systemvisited Oct 4 2021) is similar in shape and size to the Choice* devices, but also has a port for a nebulizer to provide therapy during patient inhalation.

\section{Aerobika* (Trudell Medical International/ Monaghan Medical Corp.)}

The Aerobika* OPEP device (https://www. trudellmed.com/products/aerobika-opep-device and https://www.monaghanmed.com/aerobikahealthcare-professional/-visited Oct 4 2021) has a compact handheld design through which the patient exhales via its mouthpiece against a manually adjusted variable resistance created by a one-way valve housed within a cartridge located inside the chamber housing (Fig. 6b). It is approximately $11 \mathrm{~cm}$ in length from the mouthpiece to the rear of the device, $10.5 \mathrm{~cm}$ deep and $3 \mathrm{~cm}$ wide. There are five resistance settings adjustable by means of an externally mounted lever-dial extending from the chamber and located towards the base of the device beneath the mouthpiece. The bottom part of the chamber housing can be removed for cleaning by pushing in two tabs located at front and rear faces of the device. Reassembly is assured by audible clicks as the tabs lock the base securely when re-mounted to the upper portion of the case. The device can only be reassembled one way. 


\section{Flutter* (Axcan-Scandipharm, now AbbVie} Inc.(USA))

The exterior of the Flutter* OPEP device (https://evergreen-nebulizers.co.uk/uploads/ files/Manuals/flutter.pdf-visited Oct 4 2021) is shaped like a shortened tobacco smoker's pipe just under $6 \mathrm{~cm}$ in length with a mouthpiece proximal to the user, a plastic protective and perforated cover at the distal end, with a highdensity stainless-steel ball resting in a plastic annular cone on the inside of the enclosure (Fig. 6c). This cover can be removed to permit cleaning of the interior surfaces of the device. Although the Flutter* device was the first of its kind to be introduced to market, many devices with a similar look and functionality have since become available (i.e., the PARI OPEP* device (PARI Respiratory Equipment, Midlothian, VA)). During exhalation, the position of the $1.9-\mathrm{cm}$ diameter steel ball is determined by an equilibrium between the pressure of the exhaled air acting in opposition to the force of gravity on the ball and is modified by the angle of the cone in contact with the ball. As the ball oscillates in position, it successively enlarges and closes the gap between the ball surface and support cone, with the user removing the device from their mouth to inhale. This process repeats several times during each exhalation to create the OPEP flow profile waveform. The device can be used with the patient sitting upright, recumbent or supine, however the bowl must be orientated in the upward direction for the device to function as intended [41]. Since the device is gravity-dependent, the angle at which it is held affects the amount of effort required to initiate ball vibrations that generate the OPEP waveform. There is no other means for controlling the oscillation frequency and amplitude [42]. Olsén et al. have observed that although the position-dependence of this device maybe an advantage in certain scenarios, it is likely to be difficult for many patients to achieve consistent expiratory flow resistance by themselves [41]. As well as being made aware of the physiological aim with the treatment they must be trained and repeatedly evaluated to utilize this device optimally on an ongoing basis [41]. Presumably, the same consideration also applies to other OPEP devices whose expiratory flow resistance is gravity- and therefore position-dependent, however little data have been published to date to verify the situation.

\section{Lung Flute* (Medical Acoustics LLC)}

In contrast with most OPEP devices, the exterior of the Lung Flute* (https://www.physio-pedia. com/The_Lung_Flute_-_An_Acoustic_Device_ for_Airway_Clearance-visited Oct 4 2021) resembles a flute-like musical instrument, $38.6 \mathrm{~cm}$ in length with a slightly flared exit (Fig. 6d). Rather than using periodic partial airway occlusion to create OPEP, it operates on the principle of generating acoustic energy by vibration of a reed located in the exhalation flow pathway [61]. When the user exhales with minimal force (equivalent to a pressure of at least $2.5 \mathrm{~cm} \mathrm{H}_{2} \mathrm{O}(245 \mathrm{~Pa})$ ), a loud (110-115 dB) sound wave having a frequency between 16 and $22 \mathrm{~Hz}$ is formed [62]. The reed should be replaced about every two weeks, depending on the frequency of use. The manufacturer recommends washing the interior of the device when disassembled for reed replacement.

\section{PocketPEP* (D R Burton Healthcare)}

The external appearance of the PocketPEP* device (https://drburtonhpi.com/products/ \#PocketPEP-visited Oct 4 2021) is a flattened cylinder close to $10 \mathrm{~cm}$ in length, with a mouthpiece at one end (Fig. 6e). OPEP is generated by means of a flapper-valve configured to rotate the blocking segment located in the expiratory flow pathway repeatedly between the closed position and the open position in response to a flow of air. A mechanical stop prevents the vane rotating full circle about its support. Although two flow resistance levels are possible depending on the side facing upwards, there is no other means to augment OPEP settings. The device disassembles into six small components for cleaning.

\section{Quake* (Thayer Medical)}

The Quake* OPEP device (https:// thayermedical.com/products/quake/—visited Oct 4 2021) is also small, being approximately $10 \mathrm{~cm}$ long by $5 \mathrm{~cm}$ wide. It is curved in external appearance with the outer housing 
transitioning through a right-angle bend to the outer barrel located distal to the mouthpiece (Fig. 6f). The interior of this barrel contains a series of ridge-like protrusions located equidistant around its cylindrical form. The inner barrel contains a series of slits evenly spaced around the exterior section. A handle that is affixed to the inner barrel is manually rotated by the user during either inhalation or exhalation, so that the airflow is occluded when the slots are unaligned with the ridges. The oscillation frequency is controlled by the speed at which the handle is rotated. Although there is no separate PEP setting adjustment, the OPEP profile is affected by the handle rotation velocity. Thus, moving the handle slowly creates a low-frequency oscillation and a higher pulsatile expiratory pressure. Rotating the handle more rapidly results in higher-frequency oscillations while at the same time decreasing the magnitude of the expiratory pressure pulse pressure waveform [41].

\section{RC-Cornet* and RC-Cornet* Plus (Cegla) Devices}

The RC-Cornet* device (https://www.oxigo.co/ en/cegla-rc-cornet.html-visited Oct 4 2021) has an adjustable mouthpiece/nosepiece attached to a large (approximately $20 \mathrm{~cm}$ long) curved horn-shaped body encasing a length of elastomeric hose that vibrates upon exhalation partially occluding the flow passage to create the OPEP waveform (Fig. 6g). A separate ' $\mathrm{T}$ 'adapter containing a valve has to be attached to the mouthpiece if the device is to be used with a nebulizer to deliver medication during the inhalation portion of each breathing cycle. Five resistance settings are available from low to high by rotating the body of the device against its adapter [63]. This device can be used in any position as it is claimed to be gravity independent [63], and it can be disassembled into six parts for cleaning. A newer version of this device (RC-Cornet* Plus (https://www.oxigo.co/ en/cegla-rc-cornet-plus.html-visited Oct 4 2021)) has recently become available in Europe. The manufacturer claims several improvements compared with the original device, including audible patient feedback during exhalation, a new valve design enabling both exhalation and inhalation, as well as compatibility for use with a nebulizer for medication delivery during the inhalation portion of each breathing cycle. Published performance data are, however, lacking at the present time.

\section{ShurClear* (Mercury Medical)}

The ShurClear* device (https://www. mercurymed.com/product/airway-clearancedevices/-visited Oct 4, 2021) resembles the Flutter* in both appearance and size (Fig. 6h). It also generates its OPEP pressure pulsations having frequencies in the range of 6 to $20 \mathrm{~Hz}$ by rapid movement of a captive steel ball between closed and open flow pathway positions during exhalation through the device at flow rates between 10 and $30 \mathrm{l} / \mathrm{min}$. Like the Flutter* device, the angle at which the patient holds the ShurClear* during therapy will affect the frequency of the oscillations; in the mouthpiece horizontal position, the pulsation frequency is claimed to be $14 \mathrm{~Hz}$ [64]. Also, there is no means to change OPEP profile settings. The device disassembles into five components for cleaning.

\section{Vibralung* (Westmed Inc.)}

The Vibralung* (https://westmedinc.com/ vibralung/-visited Oct 4 2021), like the Lung Flute* OPEP device operates by means of acoustically generated pressure pulsations. However, these pulses are emitted into the exhaled air pathway via a transducer controlled with a signal external battery-powered processor control unit. The Vibralung* unit is large $(10.8 \times 13.3 \times 3.2 \mathrm{~cm}$ [65] $)$ compared with most other OPEP devices (Fig. 6i). During exhalation through the mouthpiece, sound waves are applied directly to the tracheobronchial tract at frequencies that cover the range of resonant frequencies of the human tracheobronchial tract (5 to $1200 \mathrm{~Hz}$ ) [66]. The user can configure the emitted acoustic waveform to be either random noise or programmed, sequenced bursts of quasi-musical tones. Additionally, the Vibralung* device incorporates PEP capability with the inclusion of two small holes in its mouthpiece to provide resistance to exhalation [67]. The manufacturer does not recommend using the device with a facemask 
[65]. Cleaning of the non-electronic parts is readily undertaken after decoupling the transducer from the remainder of the device, which is readily taken apart for washing.

\section{VPEP* (D R Burton Healthcare)}

The vPEP* device (https://drburtonhpi.com/ products/-visited Oct 4 2021) is approximately $13 \times 3 \times 2 \mathrm{~cm}$ (Fig. 6j). It generates OPEP by movement of a flapper valve located in the flow pathway when the user exhales through the mouthpiece, like the operating principle of the PocketPEP* device. A movable slider mounted on the upper surface of the device body adjusts the flow resistance. The device disassembles into four components for cleaning by detaching the mouthpiece from the central module containing the flapper valve.

VibraPEP* (Curaplex*/Medica Holdings, LLC) The VibraPEP* device (https://www.vibrapep. com/-visited Oct 4, 2021) is like the RC-Cornet $^{*}$ in terms of exterior size and shape (Fig. 6k). Like the RC-Cornet* ${ }^{*}$ VibraPEP* contains a length of flattened flexible hose (valve) inserted inside the curved tube that defines the expiratory flow channel. When the user exhales via the mouthpiece the air pressure inside the hose increases causing buckling in the tube bend. When the peak pressure is reached, the hose end opens and is catapulted against the wall, releasing the contained air and decreasing the flow resistance. This process is repeated many times during each exhalation to generate OPEP [68]. Five resistance (therapy) settings from low to high are available by rotating the body of the device against its adapter [66]. Settings 1-3 provide continuous PEP above baseline with applied pressure and flow change. Settings 4 and 5 create erratic flow and pressure oscillations characterized by a slow increase from zero to maximum with an abrupt return to zero. The manufacturer claims that the layer of viscous mucus cannot follow these fast air movements which result in its detachment from the bronchial wall. Although not explained explicitly, the likely underlying mechanism is associated with the peak force experienced at the surface of the mucus associated with the continuously changing air pressure overcoming the adhesive bond between the mucus layer and the affected airways, an effect noted in association with the rapid onset of the high-velocity airflow associated with cough [69]. Cleaning is a relatively complicated process, but the manufacturer provides a drying aid that must be inserted into the assembly containing the hose, to ensure its interior is dried thoroughly before re-use.

\section{COMPARING THE DIFFERENT SMALL OPEP DEVICES}

\section{Overview}

There are numerous OPEP device comparisons in the public domain. However, a comprehensive comparative study is lacking that has evaluated, using a common protocol, all the devices that are currently available in North America (Table 2). This overview of in vitro performance assessment is therefore focused on those investigations where the largest number of different device types have been evaluated to draw out information having the widest applicability to this therapeutic modality. Frequently, comparisons have been made between two or three different devices, in white papers from manufacturers promoting their product(s). We have in general avoided such sources because of their limited scope, instead focusing where possible on externally peer-reviewed studies.

When comparing OPEP device types, the lack of a clear understanding as to the relative importance of the various metrics that have been used to characterize OPEP devices in the laboratory in terms of physiological effects (in vitro-in vivo correlations) is a major limitation [49]. In this context, Olsén et al. observed that an increased understanding of how PEP is produced for the spontaneously breathing patient (by these devices) is important to achieve desired treatment effects [41]. Studies that combine both in vitro measures and in vivo effects in terms of mucus clearance are therefore urgently needed to provide the necessary clarity to help device manufacturers target features that provide optimum clinical effectiveness. Performance assessments based solely on 
laboratory-acquired data may provide insights into the physical operation of these devices. However, the gold standard for comparing mucus displacement and removal remains efficacy data together with evidence of improved pulmonary function together with enhanced patient-perceived quality-of-life scoring from clinical studies with patients presenting with chronic disease. Further, the powerful tool of functional Magnetic Resonance Imaging (fMRI), discussed later in this review, can provide a direct indication of the mucus mobilization process. Although focused on the effect of the SARS-CoV-2 virus (COVID-19) rather than OPEP therapy, the recently published study by Anastasio et al. [70] captures some of the essence of what is needed by combining the subjective patient experience with objective pulmonary function measures that would be the hallmark of such investigations. Ideally, such studies would also determine a range of differing degrees of excessive mucus secretion.

\section{In Vitro Studies}

Given this situation, it is plausible to assume as a starting point when reviewing in vitro data that sufficient PEP upon which pressure fluctuations of adequate amplitude are imposed within the lungs is a requirement for the device to stent open the airways. This prerequisite is also key to enable air to penetrate regions behind the mucus and help decrease its viscosity, thereby making it easier to mobilize the accumulated secretions [41]. Furthermore, sufficient air flow must also be supplied to mobilize such secretions from the airway for subsequent expectoration or swallowing [71]. In consequence, the focus of in vitro comparisons has been on quantifying device airway pressure-time profiles (an example profile is shown on the left-hand side of Fig. 5) in terms of measurable parameters, such as the influence of exhalation flow rate as a function of time on oscillation frequency, amplitude, and duration.

Demchuk and Chatburn [37] recently reported one of the largest comparisons of the exhalation flow and corresponding pressure-time profiles for the following devices:
Acapella* DH, Acapella* DM, Acapella* Choice, ShurClear*, Aerobika*, VibraPEP*, vPEP*, and PocketPEP*. The exhalation flow rate-time profiles were simulated as a constant flow, adjusted from $5 \mathrm{l} / \mathrm{min}$ to $30 \mathrm{l} / \mathrm{min}$ in increments of $5 \mathrm{l} /$ min, except for the Acapella* DM device, where the maximum flow rate through the device was limited to $15 \mathrm{l} / \mathrm{min}$. The authors claimed this flow range was consistent with previous studies, citing it to be within the range reported by Poncin et al. [54], derived from COPD and CF patients having differing degrees of airway obstruction. Mean airway pressure (mean PEP), oscillatory flow frequency and amplitude were recorded as the primary variables of interest. An oscillation index (OSC) was based on a simplified set of oscillatory flow characteristics described by Poncin et al. [54] to facilitate device-to-device comparison, where:

$$
O S C=f_{O S C} \Delta \dot{V}
$$

$f_{O S C}$ is the oscillation frequency $(\mathrm{Hz})$ and $\Delta V$ is the flow waveform amplitude ( $1 / \mathrm{min})$.

OSC is based on a physical model developed by Chang et al. [72], who proposed that mucus clearance velocity for oscillatory flow devices is dependent on the following variables:

1. the average air velocity,

2. the ratio of the viscosity of air to the viscosity of mucus,

3. a function of the fraction of the crosssectional area of the airway blocked by mucus,

4. an "oscillation parameter", analogous to the Wormersley number [73] in a circular pipe (relating pulsatile flow frequency to viscous effects),

5. the peak inspiratory flow rate divided by peak expiratory flow rate (oscillatory flow bias ratio).

Demchuk and Chatburn, in justification for the choice of $\Delta \dot{V}$ to define the oscillatory component, commented that this parameter can be seen as mimicking small flow rate increases equivalent to "mini coughs", since the flow in their study was always in the expiratory direction, and its value varied with time following a sinusoidal relationship [37]. On this basis, they 
claimed that $\Delta \dot{V}$ provides comparable information as the flow bias ratio defined by Chang et al. [72]. Chang et al. had argued that the greater the peak flows during oscillation, the greater the shear force experienced at an air-mucus interface.

Highlights from the findings from the study by Demchuk and Chatburn [37] are summarized as follows.

1. The Acapella* devices had very different flow characteristics at the highest (high) and lowest (low) resistance settings evaluated, which in turn maximized or minimized respectively the pressure against the simulated expiratory flow. Taking OSC to be the most useful comparator of secretion removal performance, the greatest values of this parameter were achieved with the Acapella* DH device option and were near maximum at the high setting $(3800 \mathrm{~Hz}-\mathrm{l} /$ $\min$ at $30 \mathrm{l} / \mathrm{min}$ ) for the set of devices evaluated. On the other hand, the corresponding values of $O S C$ for the pediatric Acapella* DM option ( $<100$ and $500 \mathrm{~Hz}-\mathrm{l} /$ min, respectively, for low and high resistance settings) were much smaller, partly because testing was constrained to $15 \mathrm{l} / \mathrm{min}$, representing the maximum expiratory flow rate for this device. Surprisingly, corresponding OSC values obtained for the

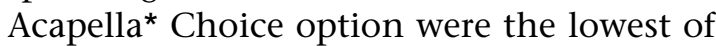
the three devices evaluated $(<50$ and $<100 \mathrm{~Hz}-1 / \mathrm{min}$, respectively, for low and high resistance settings). The maximum oscillation flow amplitudes estimated from the flow-time profiles were in the order 72,24 , and $10 \mathrm{l} / \mathrm{min}$ for the $\mathrm{DH}, \mathrm{DM}$ and Choice options, respectively. Finally, the maximum PEP achieved by both the DH and DM options was observed towards the high end of the range of the set of devices at $25 \mathrm{~cm} \mathrm{H}_{2} \mathrm{O}(2.45 \mathrm{kPa})$, whereas the corresponding value for the Choice option was lower at $15 \mathrm{~cm} \mathrm{H}_{2} \mathrm{O}(1.47 \mathrm{kPa})$.

2. The range of $O S C$ values for the Aerobika* device at the highest resistance setting $(450 \mathrm{~Hz}-\mathrm{l} / \mathrm{min}$ at $15 \mathrm{l} / \mathrm{min}$ and $3300 \mathrm{~Hz}-\mathrm{l} /$ min at $30 \mathrm{l} / \mathrm{min}$ ) was found towards the upper end of the overall range encompassed by the device set. At the lowest resistance setting, the corresponding values were reduced to 50 and $200 \mathrm{~Hz}-\mathrm{l} / \mathrm{min}$, respectively, in overall terms offering a wide range of performance for mucus displacement depending upon patient capability to operate with low or higher expiratory resistance. The maximum flow oscillation amplitude at $35 \mathrm{l} / \mathrm{min}$, was in the middle of the overall range for the set of devices evaluated. Finally, the maximum PEP achieved $\left(30 \mathrm{~cm} \mathrm{H}_{2} \mathrm{O}(2.94 \mathrm{kPa})\right)$, indicative of the potential to expand airway diameter with the prospect of permitting air penetration distal to mucus plugs, was the highest for this group of devices.

3. The range of OSC for the ShurClear* device at the low setting $(800 \mathrm{~Hz}-1 / \mathrm{min}$ at $15 \mathrm{l} / \mathrm{min}$ to $1900 \mathrm{~Hz}-\mathrm{l} / \mathrm{min}$ at $30 \mathrm{l} / \mathrm{min}$ ) was the highest of the dataset. Corresponding values at the high setting $(1500 \mathrm{~Hz}-1 / \mathrm{min}$ at 15 $1 / \mathrm{min}$ to $3800 \mathrm{~Hz}-1 / \mathrm{min}$ at $30 \mathrm{l} / \mathrm{min}$ ) were also close to the maximum values. However, in contrast to the other devices, the maximum oscillation flow amplitude varied widely between about 15 to $60 \mathrm{l} / \mathrm{min}$ from one oscillation to the next in the series. It is unclear how this intrinsic variability in performance might influence mucus mobilization. However, the PEP achieved was comparatively low and showed significant variability from one oscillation to the next, ranging from 14 to $22 \mathrm{~cm} \mathrm{H}_{2} \mathrm{O}$ (1.37 to $2.16 \mathrm{kPa})$.

4. OSC values for the VibraPEP* device were mid-range for the group of devices evaluated, varying from almost zero $\mathrm{Hz}-\mathrm{l} / \mathrm{min}$ at $15 \mathrm{l} / \mathrm{min}$ to $1500 \mathrm{~Hz}-\mathrm{l} / \mathrm{min}$ at $30 \mathrm{l} / \mathrm{min}$ for the low resistance setting to between 450 and $1900 \mathrm{~Hz}-\mathrm{l} / \mathrm{min}$, respectively, at 15 and $30 \mathrm{l} / \mathrm{min}$ for operation at high resistance. The pressure waveform was relatively complex with an intervening minor oscillation embedded within each larger pulsation; the maximum oscillation flow amplitude was close to $26 \mathrm{l} / \mathrm{min}$. The PEP achieved $(13 \mathrm{~cm}$ $\left.\mathrm{H}_{2} \mathrm{O}(1.27 \mathrm{kPa})\right)$ was one of the smallest values and comparable with that of the vPEP device. 
5. The ranges of $O S C$ values at the high resistance setting for the $\mathrm{vPEP}^{*}(<50 \mathrm{~Hz}-\mathrm{l} /$ $\min$ at $15 \mathrm{l} / \mathrm{min}$ to $450 \mathrm{~Hz}-1 / \mathrm{min}$ at 30 l/min) and PocketPEP* $(0 \mathrm{~Hz}-1 / \mathrm{min}$ at 15 $\mathrm{l} / \mathrm{min}$ to $650 \mathrm{~Hz}-1 / \mathrm{min}$ at $30 \mathrm{l} / \mathrm{min}$ ) devices were both at the low end of the spectrum for the set of OPEP devices evaluated. These values were associated with a very low flow oscillation amplitude for the $\operatorname{vPEP}^{*}(<5$ $1 / \mathrm{min}$ ) and an almost undetectable oscillatory behavior $(<1 \mathrm{l} / \mathrm{min})$ with the PocketPEP* device. Values of mean PEP (13 and $0 \mathrm{~cm} \mathrm{H}_{2} \mathrm{O}(1.27$ and $0 \mathrm{kPa})$ ) were reported for the vPEP* $^{*}$ and PocketPEP* devices, respectively.

Demchuk and Chatburn [37] counselled that it is a common misconception that a device performs well because it produces a loud noise associated with a pressure waveform having a large amplitude. They further commented that the low performance of some devices should be of concern, if it is accepted that their comparative measurements have prognostic value as to the expectation for mucus clearance. These authors acknowledged that a major limitation of their comparisons is that they provide no direct data on the physiologic effects of either PEP or OPEP. This study could also be criticized for the fact that their measurements were made with the expiratory flow rate held at a constant value, which is unrepresentative of patient exhalation flow rate-time profiles. Further, although derived from the physics of pulsatile flow through pipes, their oscillation index is not yet validated, and therefore an accepted measure for clinical benefit of OPEP therapy.

The investigation by Van Fleet et al. [50], comparing four OPEP devices (Acapella* $\mathrm{DH}$ and DM (counted as a single device), Aerobika*, Flutter* and $\mathrm{RC}^{*}$-Cornet) using a simulated CF patient exhalation model represents a more sophisticated approach. Their model involved using a breathing simulator (ASL 5000; IngMar Medical, Pittsburgh, PA, USA) to mimic the pulmonary mechanics of a pediatric patient with moderate to severe $\mathrm{CF}$, based on the data of Hart et al. [74]. Airway resistance and lung compliance were set to $17.1 \mathrm{~cm} \mathrm{H}_{2} \mathrm{O} / \mathrm{l} / \mathrm{s}$ $(1.67 \mathrm{kPa} / \mathrm{l} / \mathrm{s})$ and $42.1 \mathrm{ml} / \mathrm{cm} \mathrm{H}_{2} \mathrm{O}(430 \mathrm{ml} /$
Fig. 7 Expiratory flow waveforms for OPEP devices from Van Fleet et al. [50]. The abscissa represents the total single simulated breathing cycle time of $2.7 \mathrm{~s}$, the ordinate represents peak pressure $\left(P_{\text {peak }}, \mathrm{cm} \mathrm{H}_{2} \mathrm{O}\right)$, from a minimum of 4 to a maximum of $25 \mathrm{~cm} \mathrm{H}_{2} \mathrm{O}$, and the green horizontal line denotes the reference value of $0 \mathrm{~cm} \mathrm{H}_{2} \mathrm{O}$. Republished with permission of Daedelus Press, from Van Fkeet et al. [50]; permission conveyed through Copyright Clearance Center, Inc

$\mathrm{kPa}$ ). The base exhalation profile parameters were: (a) tidal volume $=409 \mathrm{ml}$; (b) rate per minute $=22$; $(\mathrm{c})$ inspiratory $/$ expiratory ratio $=$ 1:3.5 (0.6 s inhalation, $2.1 \mathrm{~s}$ exhalation). The setting for percentage increase and percentage release settings of the model were adjusted until a sinusoidal half-waveform with a higher, but not forceful, expiratory flow was achieved, which was defined as an "active exhalation". Each OPEP device resistance was evaluated at low, medium, and high settings, and representative exhalation waveforms are shown in Fig. 7. The following observations are evident:

1. All waveforms for the Acapella* DH device had a clear 'crescendo' effect mid-exhalation, where the oscillation amplitude is maximized and is reflective of the changes in expiratory flow from the maximum during the simulated exhalation. The amplitude of the oscillations was smallest at the high resistance setting.

2. In contrast, the highest oscillation amplitudes were evident at the high resistance setting for the pediatric Acapella* DM device, and the 'crescendo' effect was smaller regardless of the pressure setting.

3. A 'crescendo' effect was also evident with the Aerobika* device, and the oscillation amplitudes were the largest of the group regardless of resistance setting. This device also provided the most consistent magnitude of oscillations from low to high exhalation resistance setting.

4. A smaller 'crescendo' effect was also observed with the Flutter* device, but only at the medium and high resistance settings, also associated with a significant decrease in 


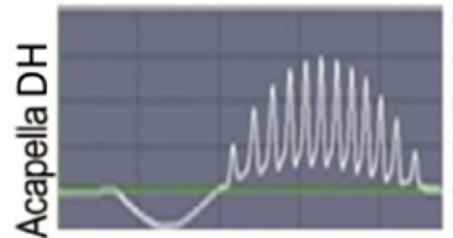

Low Resistance

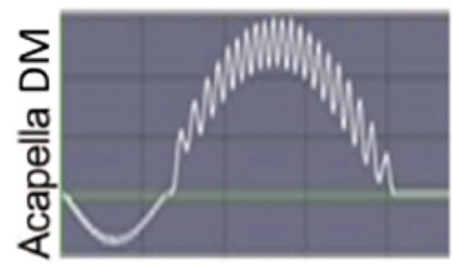

Low Resistance Medium Resistance

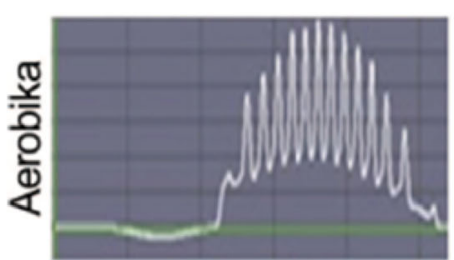

Low Resistance Medium Resistance

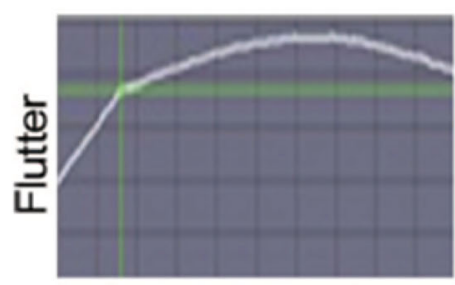

Low Resistance

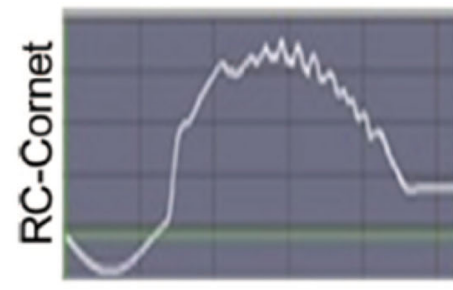

Low Resistance

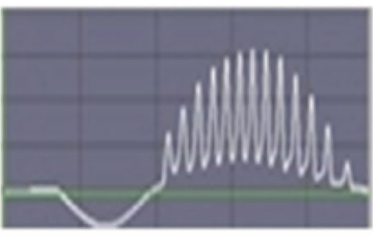

Medium Resistance
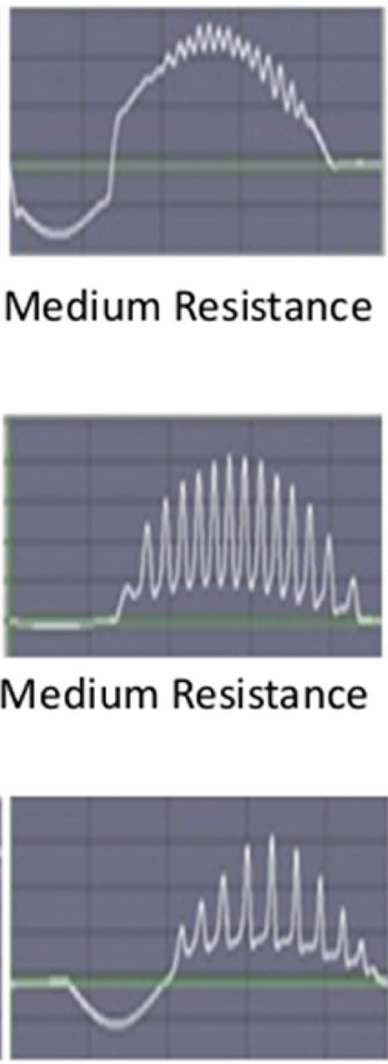

Medium Resistance

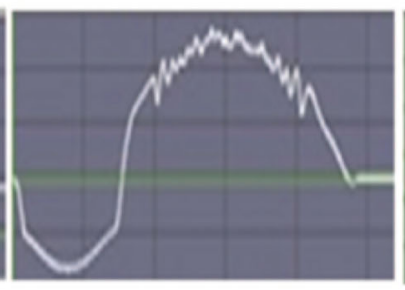

Medium Resistance

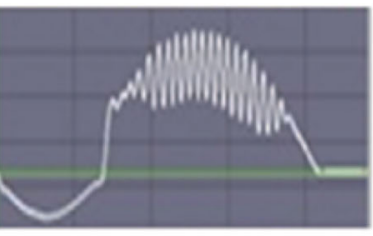

High Resistance

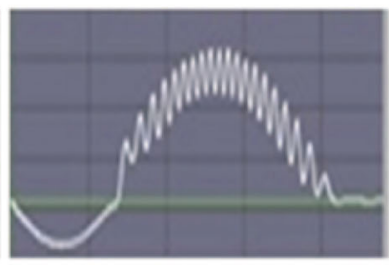

High Resistance

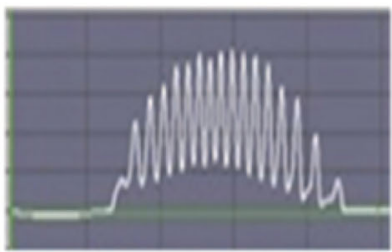

High Resistance

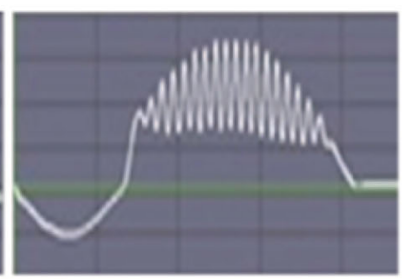

High Resistance

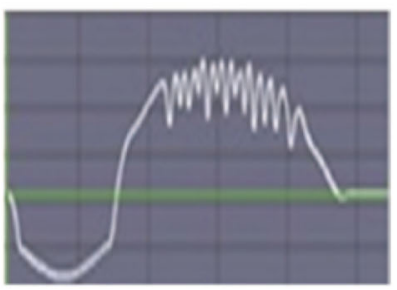

High Resistance 
oscillation frequency at the medium setting. Surprisingly, the flow-time profile was virtually smooth indicating a lack of oscillatory behavior at the low resistance setting.

5. The RC-Cornet* device also exhibited the 'crescendo' effect at all settings; however, the oscillation frequency was more variable compared with the other devices, and the magnitude of the oscillations was significantly smaller at the low resistance setting.

The results reported from an experimental study by Van Fleet et al. [50], comparing four OPEP device types, also showed that both the resistance setting and design, specifically the way the occlusion is created, affect pressure build-up during exhalation. This process influences the peak pressure $\left(P_{\text {peak }}\right)$ when active exhalation begins and the value of PEP when flow decays. They also reported the Aerobika* device provided the most consistent pressure amplitude for air-flow oscillations across the spectrum of resistance settings, producing the highest mean pressure amplitude at the medium and high resistance settings. In conclusion, these authors observed the functional variations from one device type to another may impact therapeutic effectiveness, warranting additional study to determine clinical impact. They acknowledged that their methodology, although based on a pediatric CF patient expiratory waveform, was unable to account for variations in effort or airway resistance that occur in the clinical setting before, during, and after an OPEP maneuver. Further, they were unable to mimic the changes in airway resistance that would likely take place as secretions are loosened and mobilized during OPEP therapy combined with (huff)-coughing maneuvers. It is also evident that adult breathing profiles would have been of added value in the context of assessing OPEP devices in the context of COPD/bronchiectasis, which leads to the next study.

Poncin et al. [54], based on analyses of studies such as those previously mentioned, observed that, in general, mechanical effects with OPEP devices such as PEP, oscillation frequency, and oscillation amplitude vary widely from one device type to another. These authors also affirmed the observation of Morrison and Innes [59] that clinical studies comparing the efficacy of various OPEP devices with CF patients have thus far failed to report the superiority of any one technique over another. The study by Poncin et al. [54] represents a further advance from previous OPEP device comparison attempts, in that they included expiratory profiles from three patients with COPD and CF as well as reference profiles acquired from a healthy adult. They based their four expiratory flow-time profiles on averaged data of replicate measurements from subjects with the following lung functions:

(a) healthy volunteer with a predicted value of forced expiratory volume in $1 \mathrm{~s}\left(F E V_{1}\right)$ $103 \%$ of normal,

(b) subject with COPD and $F E V_{1} \quad 71 \%$ of normal,

(c) subject with COPD and $F E V_{1} 50 \%$ of normal,

(d) subject with CF and $F E V_{1} 25 \%$ of normal.

Poncin et al. evaluated gravity-dependent OPEP devices, including the Flutter* and Pari $\mathrm{O}-\mathrm{PEP}$, as well as gravity-independent devices, such as the Acapella* Choice and Aerobika*, by means of a computer-driven flow-volume simulator (Hans-Rudolph, Shawnee, KS, USA). The exhalation profiles produced by each device-ontest operated at low, medium, and high resistance settings ( $n=3$ replicates) were divided into four equal time parts. The values of mean PEP, oscillation amplitude, and oscillation frequency generated from the middle (second and third parts) were subsequently evaluated (Table 3). The Acapella device produced the highest mean PEP and $P_{\text {peak }}$ values for each resistance setting, but the corresponding values for the other devices were in the range 12.8 to $21.2 \mathrm{~cm} \mathrm{H}_{2} \mathrm{O}$ (1.25 to $2.08 \mathrm{kPa}$ ) for $P_{\text {peak }}$ and between 7.4 and $17 \mathrm{~cm} \mathrm{H}_{2} \mathrm{O}(0.73$ and $1.67 \mathrm{kPa})$ for PEP. However, the ability to achieve both high PEP and $P_{\text {peak }}$ values beyond the minimum values at mid-expiration needed to stent open the airways $\left(10-20 \mathrm{~cm} \quad \mathrm{H}_{2} \mathrm{O} \quad(0.98-1.96 \mathrm{kPa})\right.$ [18]) is somewhat open to question. This consideration could be especially significant for COPD patients with significant hyperinflation associated with low $F E V_{1}$ [74]. This condition 
Table 3 Values of OPEP variables of interest (mean \pm SD) by device and resistance level (from Poncin et al. [54]. Republished with permission of Daedelus Press,from Poncin et al. [54]; permission conveyed through Copyright Clearance Center, Inc

\begin{tabular}{llllll}
\hline & Resistance setting & Acapella* $^{*}$ choice & Aerobika* $^{*}$ & Flutter $^{*}$ & $\begin{array}{l}\text { PARI } \\
\text { O-PEP* }\end{array}$ \\
\hline$P_{\text {peak }}\left(\mathrm{cm} \mathrm{H}_{2} \mathrm{O}\right)$ & Low & $31.3 \pm 27.8$ & $12.8 \pm 7.6$ & $16.4 \pm 4.0$ & $17.1 \pm 4.5$ \\
& Medium & $34.1 \pm 29.0$ & $15.8 \pm 8.9$ & $19.6 \pm 4.0$ & $20.3 \pm 4.4$ \\
& High & $38.4 \pm 30.2$ & $19.6 \pm 10.7$ & $21.2 \pm 4.8$ & $20.6 \pm 4.2$ \\
PEP $\left(\mathrm{cm} \mathrm{H}_{2} \mathrm{O}\right)$ & Low & $17.2 \pm 14.6$ & $7.4 \pm 4.5$ & $12.2 \pm 2.7$ & $12.4 \pm 3.3$ \\
& Medium & $18.9 \pm 15.0$ & $9.2 \pm 5.6$ & $15.4 \pm 2.4$ & $15.9 \pm 3.0$ \\
& High & $22.2 \pm 16.1$ & $11.5 \pm 6.8$ & $17.0 \pm 2.9$ & $16.7 \pm 3.1$ \\
Oscillation amplitude $(1 / \mathrm{s})$ & Low & $0.20 \pm 0.08$ & $0.22 \pm 0.09$ & $0.37 \pm 0.14$ & $0.32 \pm 0.14$ \\
& Medium & $0.17 \pm 0.07$ & $0.31 \pm 0.11$ & $0.21 \pm 0.17$ & $0.17 \pm 0.06$ \\
& High & $0.13 \pm 0.06$ & $0.30 \pm 0.05$ & $0.18 \pm 0.07$ & $0.11 \pm 0.06$ \\
Oscillation frequency $(\mathrm{Hz})$ & Low & $15.1 \pm 6.3$ & $10.5 \pm 2.9$ & $12.7 \pm 1.5$ & $13.9 \pm 1.3$ \\
& Medium & $15.5 \pm 4.9$ & $11.0 \pm 3.0$ & $15.9 \pm 1.8$ & $17.0 \pm 1.8$ \\
& High & $17.9 \pm 6.1$ & $13.3 \pm 3.9$ & $17.6 \pm 0.9$ & $17.1 \pm 2.1$ \\
\hline
\end{tabular}

may limit their capability to exhale against a flow resistance without inducing excessive respiratory muscle fatigue possibly resulting in rapid shallow breathing, much as has been observed in patients with worsening CF symptoms [75]. Poncin et al. [54] also observed that though the Aerobika* device produced lower oscillation frequency values at all resistance settings compared with the other devices, it exhibited the greatest oscillation amplitude values at the medium and high resistance levels. Oscillation amplitude is linked to the force available to mobilize secretions. This group also reported that the oscillation frequency observed with the gravity dependent devices (Flutter* and PARI O-PEP*) was less dependent with their patient-acquired expiratory profiles than the gravity independent devices (Acapella* Choice and Aerobika*), whose frequencies reduced with decreasing $F E V_{1}$ (\%). However, it is unclear if these observed decreases have meaningful impact on mucus clearance without clinical data to support their laboratory-based observations. In fairness, Poncin et al. [54] acknowledged the following study limitations:
1. the limited number of waveforms that were evaluated;

2. body temperature and saturated airway humidity were not simulated;

3. by focusing on data acquired within just the middle two segments of the expiration profile, they may have missed performance variations pertinent to the initiation and termination segments.

\section{CLINICAL PERFORMANCE STUDIES}

\section{Studies Involving Direct Lung Imaging by Functional MRI}

Before examining the selected clinical investigations that shed light on the efficacy of a particular ACT modality or modalities, it is important to be aware that the conclusions arrived at in such evaluations are limited to the mucus-generating disease that was considered. To date, there are no studies that provide comprehensive outcomes across the entire spectrum of such disease conditions. It is possible that 
conclusions that relate to patients with CF may not be applicable to patients with COPD, asthma, or non-CF bronchiectasis and vice versa.

In 1999, Pryor, in a review of physiotherapeutic modalities for airway mucus clearance that included OPEP devices, reported that clinical evidence in support of these techniques was variable, and that the literature available at the time of writing was also both confusing and conflicting [76]. He noted that many of the regimens that had been evaluated included the forced expiratory maneuver of a "huff", which probably increases the effectiveness of airway clearance. The situation has not changed much since, based on the evidence presented in a recently published Cochrane review by Morrison and Milroy, which focused more specifically on the effectiveness of airway vibratory therapies for airway clearance in people with CF [66]. Their structured review included OPEP devices and assessed outcomes from 39 clinical studies that met their inclusion criteria. Morrison and Milroy concluded that there is no clear evidence that oscillation is an effective intervention in this group of patients compared with other forms of physiotherapy. Further, they asserted that there is a lack of clinical evidence that one device is superior to another. However, in coming to an overall conclusion regarding clinical effectiveness in the light of their findings, it is important to appreciate that the patient base covered by the Morrison and Milroy review [66] did not include the much larger populations of patients with chronic diseases other than CF that also result in enhanced mucus secretion. Furthermore, they did not look for direct evidence for mucus mobilization through lung imaging techniques, instead relying on the traditional indirect measures of lung performance. In this context, it is pertinent that Svenningson et al., in their assessment of OPEP devices in COPD, acknowledged that wellestablished measurements of pulmonary function such as $F E V_{1}$ are relatively insensitive to the use of various airway clearance techniques, and that larger and longer trials are needed to measure the frequency of lung infections, preference, adherence to and general satisfaction with treatment [77]. Finally, it is worth noting that Pryor [76] asserted that if objective differences (between therapeutic modalities) are small, individual preferences and cultural influences may be significant in increasing adherence to treatment and also in the selection of an appropriate regimen or regimens for an individual patient.

The next group of studies examined in detail here have the advantage that, as well as reporting measures of lung function, the authors made use of fMRI [78] as an additional tool that enables direct visualization of airway clearance resulting from mucus plug mobilization enabled by use of OPEP therapy. The introduction of functional imaging, specifically the use of hyperpolarized helium $\left({ }^{3} \mathrm{He}\right)$ in conjunction with fMRI has made it possible to visualize the interior of the major airways of the lungs with high spatial and temporal resolution ( $1 \mathrm{~mm}$ in plane and $5-10 \mathrm{~mm}$ out of plane within a breath-hold interval) so that regions obstructed by mucus can be observed before and after clearance therapy [78].

Fain et al. reviewed the potential of this form of functional imaging, showing its applicability to examine physiologic changes in airway patency in association with a variety of diseases involving airway obstruction by mucus, including asthma, CF, and COPD [79]. They emphasized the major advantages of this imaging modality are the avoidance of ionizing radiation for the subject, together with the resolution of respiratory disease morphology and function, and its safe use across a wide variety of vulnerable pediatric, respiratory compromised, and elderly patients.

Svenningson et al., in a randomized crossover clinical investigation of the merits of OPEP therapy involving fMRI, sought to improve the evidence base for OPEP therapy. This group evaluated daily use of an OPEP device (Aerobika*) for 21-28 days in 27 COPD patients aged from 40 to 85 years, who were self-identified as sputum- $(n=14)$ or non-sputum $(n=13)$ producers [77]. Their coronal lung ${ }^{3} \mathrm{He}$ MRI imaging profiles (Fig. 8) of three sputum-producing subjects and the same number of non-sputum producing subjects, provided direct evidence in several instances for the opening of airways by mucus displacement, as well as regional 


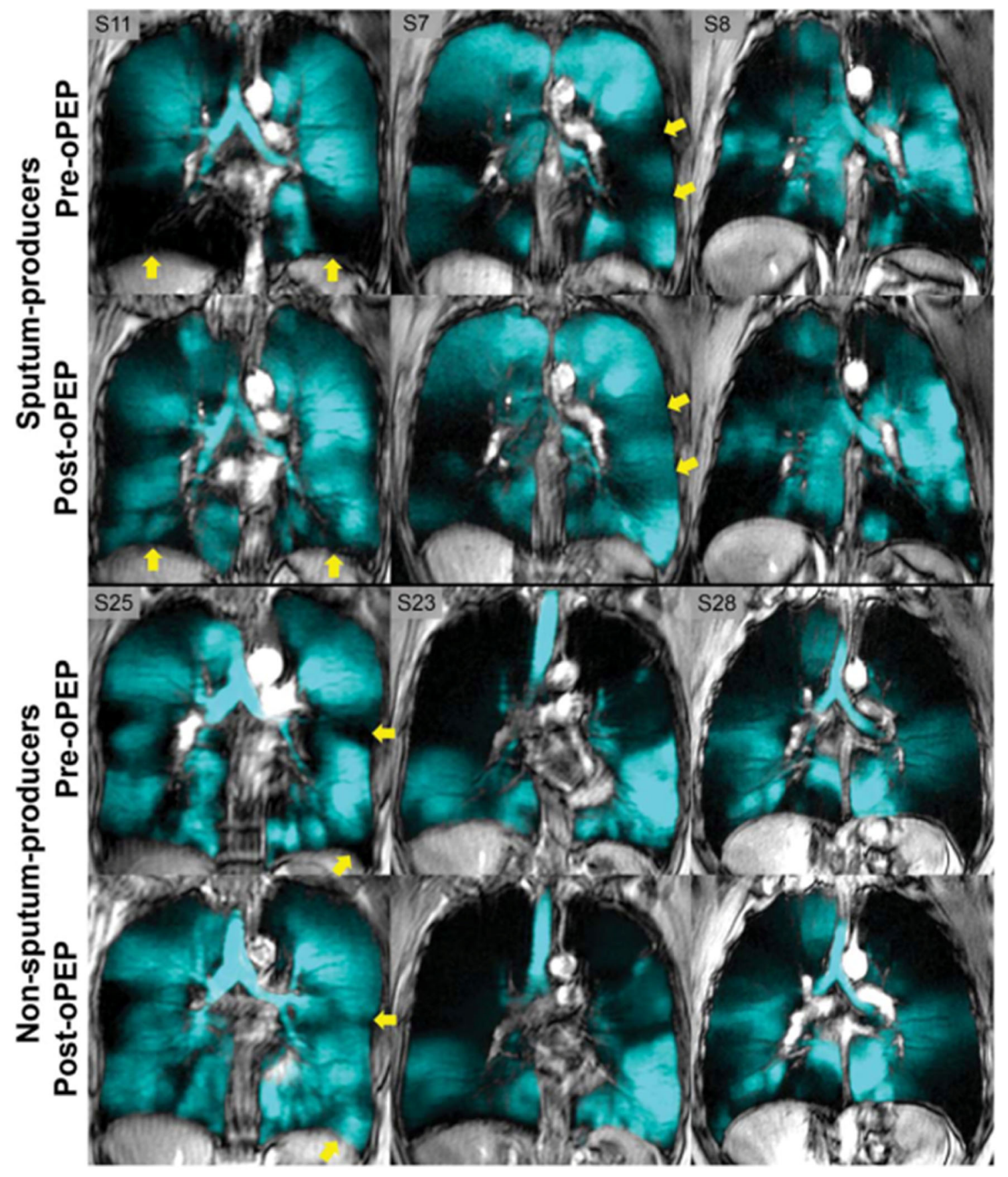

Fig. $8{ }^{3} \mathrm{He}$ fMRI ventilation in representative sputum and non-sputum-producers; pre- and post-OPEP ventilation (in cyan) registered to $1 \mathrm{H}$ anatomical MRI (in greyscale) for sputum- and non-sputum-producers. Yellow arrows identify

differences in ventilation pre-to post-OPEP therapy (denoted by yellow arrows). These changes were accompanied by improvements in regional differences in ${ }^{3} \mathrm{He}$ ventilation post-OPEP-from Svenningson et al. [77] [Republished with permission of Taylor and Francis from Svenningson et al. [77]; permission conveyed through Copyright Clearance Inc.]

lung function assessed by both $F E V_{1}$ and $F V C$, exercise endurance capability assessed by the 6-min walk distance test (6MWD), and patient 


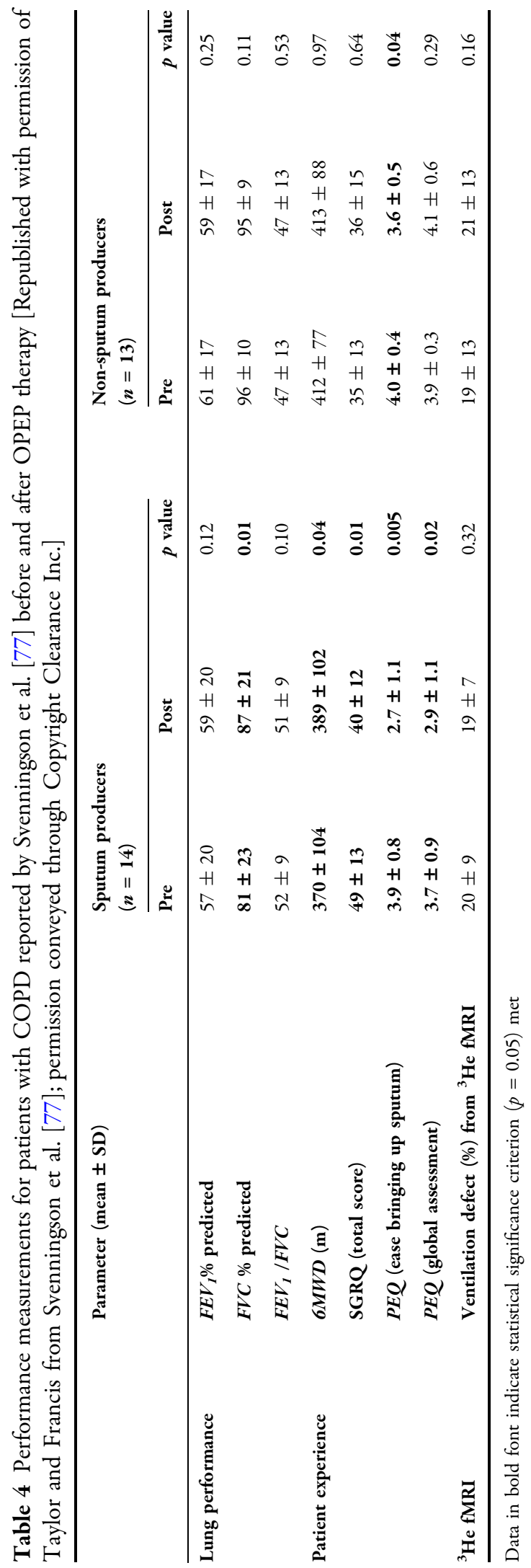

feedback via St George's Respiratory Questionnaire (SGRQ) total-scores (Table 4). The lung performance measures were largely insensitive to OPEP therapy, confirming previous observations [66]. However, with their sputum-producer cohort, they obtained a small, but significant (paired $t$ test; $p=0.01$ ) improvement in $F V C$ (mean $\pm \mathrm{SD})$ from $81 \pm 23 \%$ to $87 \pm 21 \%$ predicted. Looking at measures of patient experience for the same cohort, they also observed small but significant improvements in 6MWD from $370 \pm 104 \mathrm{~m}$ to $389 \pm 102 \mathrm{~m}(p=0.04)$, in total SGRQ score from $49 \pm 13$ to $40 \pm 12(p=0.01)$, and in the portion of the patient ease questionnaire (PEQ) regarding ease of bringing up sputum from $3.9 \pm 0.8$ to $2.7 \pm 1.1 \quad(p=0.005)$. The global assessment from the PEQ was also improved for this cohort, from $3.7 \pm 0.9$ to $2.9 \pm 1.1$ $(p=0.02)$. Importantly, the changes in the corresponding values for the non-sputum producing cohort were generally smaller and statistically insignificant $(p \geq 0.05)$, except for improvement in PEQ global assessment $(p=0.04)$. This outcome suggests that a link may exist between excessive sputum production and patient-perceived outcomes. Although the overall measure of percentage ventilation defects (VDP (\%)) derived by image analysis [80] from the ${ }^{3} \mathrm{He}$ fMRI imaging pre-and post OPEP for the sputum producing cohort was statistically insignificant $(p=0.32)$, this global outcome measure masked clinically relevant postOPEP VDP improvements that were observed in six of the 14 patients. The increase in areas highlighted in cyan for the images from patients S7 and S11 post OPEP (Fig. 9) provides direct evidence for the opening and/or recruitment of previously obstructed airways. Interestingly, VDP improvements post-OPEP were also observed for all three of the non-sputumproducers. In explanation of this counterintuitive outcome, Svenningson et al. [77] suggested that when crossed over from no therapy to daily OPEP use as opposed to the patients who were assigned to being crossed in the other direction, non-sputum-producers sensed a modest improvement in how easily they could cough up any sputum at all. Although the ease at which the patient can mobilize mucus for 
subsequent expectoration may not markedly affect lung performance measures, mucus removal has important benefits associated with the avoidance of opportunistic infection from pathogens $[16,81,82]$. Furthermore, their findings are pertinent with the more general observation that, despite the limitation of this metric especially with children, who may swallow their mucus secretions or contaminate them with saliva [83], increased expectorated sputum volume is associated with the use of PEP and enhanced by OPEP therapies in patients with chronic obstructive lung diseases resulting in excessive mucus accumulation in the airways $[81,82]$.

In another similar study undertaken about the same time, Svenningsen et al. used their fMRI imaging technique to evaluate regional abnormalities in the lungs and response to airway clearance therapy in 15 non-CF patients aged $69 \pm 10$ years with bronchiectasis

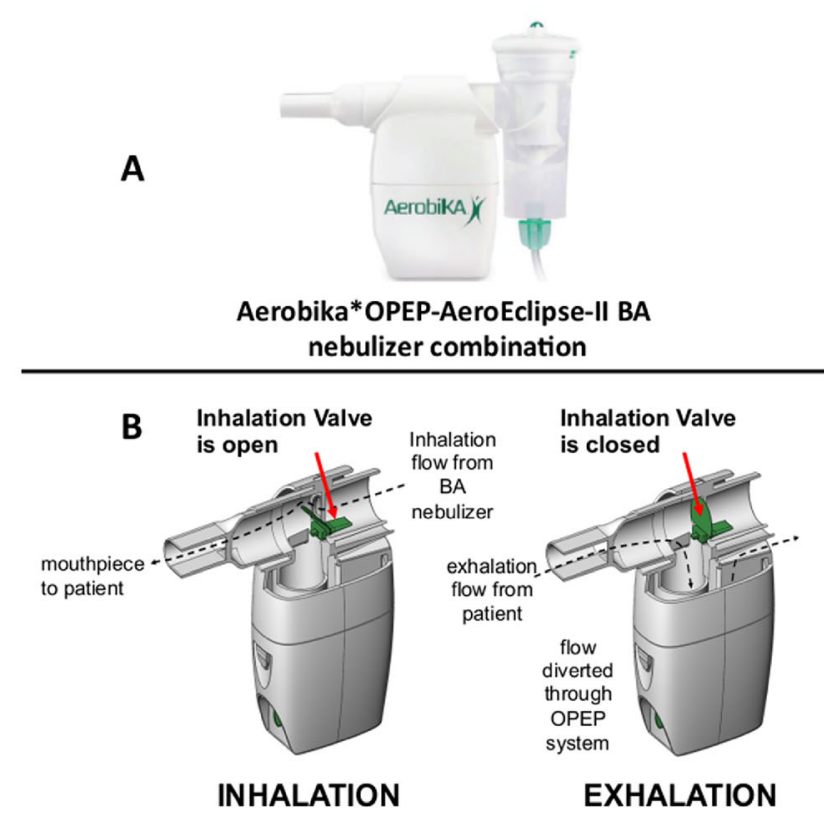

Fig. 9 A Assembled Aerobika* OPEP_AeroEclipse* BA Nebulizer Combination; B Flow pathways through the OPEP-BA nebulizer combination during patient delivered with the Aerobika* OPEP device [85]. Their investigation also included the same number of healthy patients as controls. Radiological evidence of mucus plugging, and damaged airways was revealed in symptomatic patients with a previous computed tomographic (CT) diagnosis of bronchiectasis. Their ${ }^{3} \mathrm{He}$ fMRI imaging showed heterogeneously distributed ventilation defects in those lobes with CT evidence of bronchiectasis. The defects were significantly greater and/or more numerous than in lobes without bronchiectasis. They again observed from the data for the 14 patients with bronchiectasis that indirect lung function measures were unaffected by OPEP therapy. However, the ease of bringing up sputum was slightly enhanced $(p=0.048)$ by this treatment, and the global patient experience assessment also indicated a significant improvement $(p=0.01)$. Despite the lack of evidence in this study for improvements in 6MWD distance and

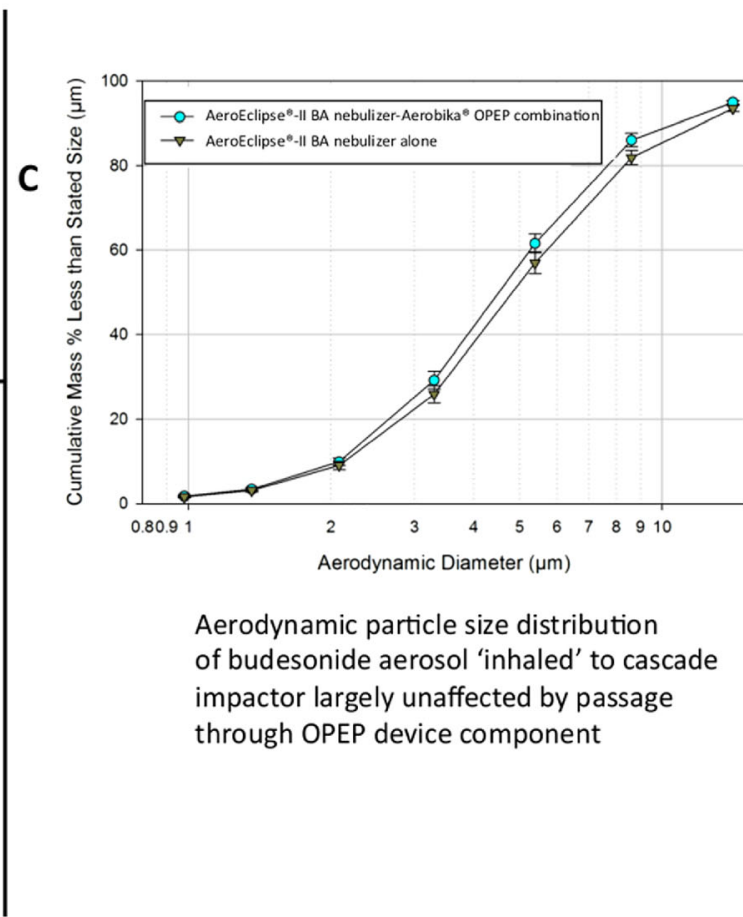

inhalation and exhalation; C Effect of passage through OPEP device on aerodynamic particle size distribution of BA nebulizer-generated budesonide suspension aerosol (from Mitchell et al. [112]) 
SGRQ total score, the overall outcome confirms the finding from their other study [77] that OPEP therapy can be effective at mucus clearance and, from the patient perspective, provides a more satisfactory experience at being able to expectorate mucus secretions that have been mobilized. Although the overall VDP measures were unaffected, further data analysis by lung region revealed that the post-OPEP change was significantly different $(p=0.003)$ both for lobes with $(\triangle V D P=-1 \%)$, and without $(\triangle V D P=$ $2 \%)$ CT evidence of bronchiectasis. They concluded, from the latter unexpected outcome, that there could be abnormalities associated with bronchiectasis and/or mucus plugging in the smaller airways, beyond the resolution limits of CT.

\section{Other Clinical Studies Evaluating OPEP Therapy}

Several clinical studies have compared patient outcomes with different OPEP devices or between OPEP and other forms of ACT. Often the driver for comparisons between OPEP devices has been the desire to demonstrate equivalence to a predicate device of the same function in support of a regulatory authorization for a pre-market authorization [86]. As a result, the outcomes often provide little insight into the applicability of OPEP therapy in general terms beyond the bounds set by the device comparison itself. Nevertheless, the studies described herein are included because they each provide some insight into potential clinical benefits. A further consideration when examining outcomes from clinical studies, is that it is difficult to quantify the volume of mucus swallowed compared with that expectorated [83, 87]. This limitation must be borne in mind when evaluating the significance of changes in measures of sputum volume.

Alghamdi et al. reported the outcomes from a review of 77 articles of OPEP devices used as an ACT for patients with COPD, from which they undertook detailed data analysis from six randomized control trials as well as a further two cross-over studies [88]. The investigations included one or more from the following devices: Acapella* (model not stated by study originators), Aerobika*, Flutter*, Lung Flute* and RC-Cornet* ${ }^{*}$ Following pooled analysis of the data, they found that there is low-grade evidence for the use of these devices being associated with decreased COPD symptoms and exacerbations (odds ratio (OR) 0.37, 95\% CI range from 0.19 to 0.72 ), as well as enhanced exercise capacity based on 6MWD, with the overall mean difference being $49.8 \mathrm{~m}$ (95\% CI range from 14.2 to $85.5 \mathrm{~m}$ ); $p=0.009]$ ). They concluded that OPEP therapy can be beneficial for patients with COPD, cautioning that (statistical) confidence related to group sizes demonstrating an effect is currently low. They reported that there is a need for further, higherquality studies to examine their long-term efficacy in COPD as well as to identify specific patient COPD phenotypes that are more likely to respond.

Bourbeau et al. also recently widened the scope of assessing the clinical applicability of OPEP-based therapy in a review that spanned studies undertaken between 1998 and May 2018 across the spectrum of obstructive lung disease [89]. This group examined the issue to identify care gaps, mainly from the Canadian perspective, as well as to provide suggestions for appropriate use. They created a useful comparison of features important from the patient perspective for the different OPEP devices available in the country (Table 5). They provided the following observations from the clinical perspective:

1. Given the low-risk safety profile and body of evidence now available across several different devices, the incorporation of an OPEP device into treatment plans of COPD, non-CF bronchiectasis and CF patients could be considered when airway clearance therapy is thought to be of value.

2. OPEP devices do not all provide the same benefits to patients and may not be interchangeable. They operate differently, produce different pressure pulse waveforms, differ in terms of usability and cleaning and are supported by varying levels of clinical evidence, the preponderance being related 
to the Aerobika ${ }^{\circledR}$ and Flutter ${ }^{\circledR}$ devices, followed by the Acapella ${ }^{\circledR}$ device group.

3. The choice of an OPEP device should be based on the published evidence, cost, and patient preference.

4. When OPEP devices are prescribed, patients should be taught which benefits to expect, and how to use and clean the device as per instructions for use.

5. Training should also be provided in performing a huff cough to expel the mucus that may have been loosened and mobilized by the device.

Bourbeau et al. [89] also commented on the small patient numbers and short study durations associated with existing clinical evaluations of these devices, observing that many investigations are limited to comparisons between two different devices with interpretations that are of questionable value. A good example of this practice, discovered while preparing this overview, is a recent comparison of the Acapella* (model unspecified) and RCCornet* devices reported by Shabari et al. [90]. This group undertook a randomized cross-over study involving 40 adult patients having a history of sputum expectoration of more than $30 \mathrm{ml}$ per day, diagnosed to have bronchiectasis. Their investigation was very limited in scope, with just sputum volume as the outcome measure, resulting in a larger change in volume from $29.33 \pm 6.95 \mathrm{ml}$ pre-use to $36.58 \pm 7.21 \mathrm{ml}$ post-use for the RC-Cornet, compared with corresponding values of $35.47 \pm 7.17 \mathrm{ml}$ and $34.63 \pm 9.03 \mathrm{ml}$, respectively, for the Acapella* device. Given the already mentioned limitations associated with the risk of swallowing secretions as well as mixing with saliva, the reported precision is likely unjustified, and the claim for increased sputum clearance following the use of RC-Cornet* device is of doubtful value. It is notable that Valente et al. [91], who also examined expectorated sputum in an observational study of a single cohort of 8 adult patients with bronchiectasis went significantly further by analyzing the rheological properties of their samples using a simulated cough machine. They compared OPEP treatment (Flutter* VRP1 device) versus PEP therapy (using the Flutter* device after removing the ball and occluding as many orifices as was necessary to produce PEP equivalent to the pressure reached by patients when using the unmodified OPEP device). Such measures of mucus mobility are intuitively likely to be of greater relevance to the prediction of likely clearance efficacy by PEP or OPEP therapies. Valente et al. [91] also determined relative transport velocity, contact angle measurement and displacement as more reliable markers of efficacy. Participants underwent two procedures at random on different days: PEP and OPEP therapies compared with no

Table 5 User-important features for OPEP devices available in Canada (adapted from Bourbeau et al. [89]) [Republished with permission of Taylor and Francis from Bourbeau et al. [89]; permission conveyed through Copyright Clearance Inc.]

\begin{tabular}{lllllll}
\hline Feature & \multicolumn{2}{l}{ OPEP device } & & & \\
\cline { 2 - 7 } & Acapella* $^{*}$ & Aerobika* $^{*}$ & Aerosure* & Flutter* $^{*}$ & Lung flute* & Quake* $^{*}$ \\
\hline Use in any orientation & $\mathrm{Y}$ & $\mathrm{Y}$ & Not applicable & $\mathrm{N}$ & $\mathrm{N}$ & $\mathrm{Y}$ \\
Inhale and exhale through device & $\mathrm{Y}$ & $\mathrm{Y}$ & $\mathrm{Y}$ & $\mathrm{N}$ & $\mathrm{N}$ & $\mathrm{Y}$ \\
Adjustable resistance settings & $\mathrm{Y}$ & $\mathrm{Y}$ & $\mathrm{N}$ & $\mathrm{N}$ & $\mathrm{N}$ & $\mathrm{N}$ \\
Dismantlable for cleaning & $\mathrm{Y}^{*}$ & $\mathrm{Y}$ & $\mathrm{Y}$ & $\mathrm{Y}$ & $\mathrm{Y}$ & $\mathrm{Y}$ \\
Dishwasher safe & $\mathrm{Y}$ & $\mathrm{Y}$ & $\mathrm{N}$ & $\mathrm{N}$ & $\mathrm{N}$ & $\mathrm{Y}$ \\
Multiple disinfection options & $\mathrm{Y}$ & $\mathrm{Y}$ & $\mathrm{N}$ & $\mathrm{N}$ & $\mathrm{N}$ & $\mathrm{Y}$ \\
Can be used with a nebulizer & $\mathrm{Y}$ & $\mathrm{Y}$ & $\mathrm{N}$ & $\mathrm{N}$ & $\mathrm{N}$ & $\mathrm{N}$ \\
\hline
\end{tabular}

${ }^{*}$ Choice and duet models only; $Y$ Yes, $N$ No 
treatment as the control. The outcomes were similar for the three groups and across the three measurements for each group, However, interestingly, the measurement of transport velocity (associated with the ability to mobilize the secretions in the first place, appeared relatively sensitive to treatment mode: OPEP therapy (Flutter* VRP1 device: median 0.6, 95\% confidence interval 0.53-0.73; PEP therapy: median $0.78,95 \%$ confidence interval $0.53-0.92$; control: median $0.63,95 \%$ confidence interval 0.51-0.79).

Other studies have also provided insight as to how OPEP therapy compares with the traditional ACT methods. For example, the investigation by Pryor et al. [24] with 65 patients aged from 17 to 63 years diagnosed with CF. examined how two different devices (RC-Cornet* and Flutter*) compare with outcomes using active cycle of breathing techniques (ACBT), autogenic drainage (AD) and PEP. This group reported no statistical difference between either the OPEP devices or between this treatment modality and the traditional methods based on $F E V_{1}(p=0.35)$ as the lung performance measure. In consequence, they concluded that each regimen can and should be adapted to suit the individual patient. More importantly, each patient should be able to adapt their regimen at the time of, and during each treatment session. It follows that a focus on patient quality of life should be a priority when considering appropriate ACT regimen(s).

\section{OPEP Therapy and Health Care Resource Utilization Including Medication Usage}

Most chronic diseases involving mucus hypersecretion, including COPD, given the relatively larger number of affected patients, have significant long-term healthcare resource implications associated with the frequency of exacerbations and their severity. Many patients are receiving oral corticosteroids to reduce airway inflammation, even though the optimal strategy for dosing and administration of these medications in the context of COPD symptom management, continues to be debated [92]. Furthermore, post-operative pulmonary complications are particularly common in patients who have undergone cardiac, thoracic, or upper abdominal surgery, involving additional significant health care resource utilization $[93,94]$. Unfortunately, there are currently few comprehensive studies that have investigated the wider impact of inadequate airway mucus clearance, and those that exist provide insights relate to only a few OPEP/PEP device types. There is therefore a need for further research that expands the knowledge base by comparing how the many different OPEP/PEP devices available perform in this respect.

In 2019, Milan et al. [84] reported a prospective single-center trial with hospitalized COPD patients with significant mucus production receiving OPEP therapy with the primary endpoint being hospital length-of-stay as a health care resource utilization metric. The investigation study compared PEP therapy $(n=47)$ with OPEP treatment $(n=44)$. They further examined their data with results from a historical cohort matched 2:1 by age, gender and season of admission who had received no OPEP/PEP therapy $(n=182)$, serving as the control group. The Acapella* Choice OPEP device had its oscillatory mechanism modified for use when delivering PEP therapy. The procedure was performed three times daily according to instructions for use when delivering OPEP treatment, including several "huff coughs" following use. They found that the hospital length of stay (mean \pm SD) was significantly shorter $(p=0.02)$ at $5.1 \pm 3.9$ days for the treatment group (PEP/OPEP) compared with $6.6 \pm 5.1$ for the control group. However, by not separating the data from the patients receiving PEP therapy from the OPEP cohort, it is not possible to determine how much of the improvement in length of stay was the result of either of the treatments. They also found that the median hospital length of stay was $3.2(95 \%$ CI 3.0-4.3) days for patients in the OPEP group and 4.8 (95\% CI 3.9-6.1) days in the PEP group $(p=0.16)$. Although this outcome was statistically insignificant by a narrow margin, it enabled them to claim the addition of an oscillating component to PEP therapy is suggestive of a further reduction in hospital length of stay compared with no PEP/OPEP therapy. 
They correctly concluded that comprehensive (larger) multicenter randomized controlled trials would be needed to confirm that finding.

Burudpakdee et al. widened the assessment of the clinical impact of OPEP therapy beyond the previously discussed clinical measures in this overview, to report economic benefits in a real-world setting associated with re-hospitalization for further exacerbations [95]. This group further accounted for the increased cost of managing severe compared with moderateto-severe exacerbations by breaking out the two conditions separately in their data analysis. A moderate-to-severe exacerbation was defined as the occurrence of either a hospitalization or an emergency department visit with a diagnosis for chronic bronchitis or COPD. A severe exacerbation, as a subset of the moderate-to-severe category, was defined as a hospitalization with a diagnosis of chronic bronchitis or COPD. Their study design examined the effectiveness of OPEP therapy (Aerobika* device) in reducing US hospital emergency department (ED) visits, hospital re-admission and related costs. They examined the records of a cohort of 405 COPD patients who had a history of exacerbations. This pool of data was obtained from 650 hospitals in 46 states comprising 7 million annual inpatient stays and 60 million annual outpatient visits between 2013 and 2015. These patients were propensity score-matched to COPD patients who did not use any OPEP device as controls. This approach helped reduce intrinsic bias due to confounding variables that could have been found in an estimate of the OPEP therapy had the outcomes simply been compared between the cohort that had received the treatment versus those that had not. Treatment outcomes in the two cohorts were evaluated using bivariate chi-square tests, and the difference in sample means between the two groups was assessed using Student's $t$ test of independent samples (significance at $p<0.05$ ). A t 30 days post index (first) hospitalization (Table 6), they found that $18.5 \%$ of subjects using the OPEP device had a moderate-to-severe exacerbation compared with $25.7 \%$ in the control cohort $(p=0.014)$. In comparison, $13.8 \%$ of subjects treated by OPEP therapy had a severe exacerbation versus $19.0 \%$ in the control group $(p=0.046)$. The mean per-patient cost of moderate-to-severe exacerbations in the OPEP device-treated cohort (\$2975) was significantly lower than the equivalent cost for the control group (\$6065) $(p=0.008)$. Likewise, the mean cost per patients experiencing severe exacerbations was $\$ 2838$, compared to $\$ 5871$ for the controls $(p=0.009)$. Applying a generalized linear model with covariate adjustments to control for potential confounders to the data, the per-patient cost of moderate-to-severe exacerbations in the OPEP cohort was shown to be $34 \%$ lower $(p=0.012)$ than for the control group.

More recently, Burudpakdee et al. extended their approach by assessing the impact of adding the Aerobika* OPEP device to the standard of care on healthcare resource utilization and costs in US-based post-operative patients related to a cardiac, thoracic, or upper abdominal surgical procedure undertaken between 1 September 2013 and 30 April 2017 [96]. The same proprietary source as used for the previous investigation [95] was evaluated to obtain the data pool. The outcomes reported within 30 days of hospital discharge (Table 7) reveal that this OPEP device is associated with significantly fewer re-hospitalizations $(13.9 \%$ vs. $22.9 \% ; p=0.042$ ), and shorter length of stay (mean \pm SD: $1.25 \pm 4.04$ vs. $2.60 \pm 8.24$ days). OPEP therapy lowered costs associated with inpatient events compared to the pre-existing standard-of-care (mean SD: $\$ 3670 \pm \$ 13,894$ vs. $\$ 13,775 \pm \$ 84,238 ; p=0.057)$, based on the 2011 American Association for Respiratory Care (AARC) Guideline [97]. Adjusted analyses to control for remaining imbalance after PS matching indicated that hospitalization costs were $80 \%$ lower for the cohort receiving OPEP therapy versus existing standard-of-care $(p=0.001)$. Though not confined to patients with pre-existing mucus-caused obstructive lung disease, this analysis nevertheless provides support for an improved post-operative experience when OPEP therapy is utilized, and demonstrated, from the societal viewpoint, an improvement in costs associated with rehospitalization.

Rather than using an existing non-OPEPbased standard-of-care as the reference 
Table 6 Exacerbations and associated costs reported by Burudpakdee et al. [95] for a cohort of COPD patients $(n=405)$ treated with Aerobika* OPEP therapy compared with an equivalent number of non-OPEP-treated patient controls [Original article created under the terms of the Creative Commons Attribution-Non-Commercial 4.0 international license (http://creativecommons.org/licenses/by-nc/4.0/: used by permission of the authors]

\begin{tabular}{|c|c|c|c|c|}
\hline Severity & Exacerbation measure & Aerobika* OPEP & Matched controls & $p$ value \\
\hline \multirow[t]{3}{*}{$\begin{array}{l}\text { Moderate-to- } \\
\text { severe }\end{array}$} & $\begin{array}{l}\text { Number of patients in cohort experiencing an } \\
\text { exacerbation }(n(\%))\end{array}$ & $75(18.5)$ & $104 \pm 25.7$ & 0.014 \\
\hline & Exacerbations per patient (mean \pm SD) & $0.23 \pm 0.56$ & $0.30 \pm 0.55$ & 0.099 \\
\hline & Cost per exacerbation (mean $\pm \mathrm{SD})$ & $\$ 2,975 \pm \$ 11,529$ & $\$ 6,065 \pm \$ 20,275$ & 0.008 \\
\hline \multirow[t]{3}{*}{ Severe } & $\begin{array}{l}\text { Number of patients in cohort experiencing an } \\
\text { exacerbation }(n(\%))\end{array}$ & $56(13.8)$ & $77(19.0)$ & 0.046 \\
\hline & Exacerbations per patient (mean $\pm \mathrm{SD})$ & $0.15 \pm 0.40$ & $0.21 \pm 0.45$ & 0.048 \\
\hline & Cost per exacerbation (mean $\pm \mathrm{SD})$ & $\$ 2,838 \pm \$ 11,516$ & $\$ 5,871 \pm \$ 20,134$ & 0.009 \\
\hline
\end{tabular}

Data in bold font indicate statistical significance criterion $(p=0.05)$ met

Table 7 COPD patient outcomes $(n=144$ patients) within 30 days post-discharge from US hospitals comparing OPEP therapy with current standard-of-care (from Burudpakdee et al. [96])

\begin{tabular}{|c|c|c|c|}
\hline Measure & $\begin{array}{l}\text { Aerobika* OPEP } \\
\text { device therapy }\end{array}$ & $\begin{array}{l}\text { Current standard- } \\
\text { of-care }\end{array}$ & $p$ value $^{1}$ \\
\hline $\begin{array}{l}\text { Number (proportion) of patients with at least one all cause } \\
\text { rehospitalizations }(n,(\%))\end{array}$ & $20(13.9 \%)$ & $33(22.9 \%)$ & 0.042 \\
\hline $\begin{array}{l}\text { Number (proportion) of patients with a procedure code for chest } \\
\text { X-ray during rehospitalizations }(n(\%))\end{array}$ & $16(11.1 \%)$ & $29(20.1 \%)$ & 0.037 \\
\hline Number of all-cause rehospitalizations per patient (mean $\pm S D$ ) & $0.17 \pm 0.44$ & $0.28 \pm 0.56$ & 0.038 \\
\hline $\begin{array}{l}\text { Total length of stay (days) of the rehospitalization (not including } \\
\text { the index hospitalization }{ }^{2} \text { (mean } \pm S D \text { ) }\end{array}$ & $1.25 \pm 4.04$ & $2.60 \pm 8.24$ & 0.047 \\
\hline $\begin{array}{l}\text { Time to first all-cause rehospitalization in days, among patients who } \\
\text { had at least one all-cause rehospitalization (mean } \pm \text { SD) }\end{array}$ & $12.65 \pm 7.68$ & $10.30 \pm 8.32$ & 0.188 \\
\hline $\begin{array}{l}\text { Total all-cause costs of inpatient events (not including the index } \\
\text { hospitalization) (mean } \pm \text { SD) }\end{array}$ & $\$ 3,670 \pm \$ 13,894$ & $\$ 13,755 \pm \$ 84,238$ & 0.057 \\
\hline
\end{tabular}

\footnotetext{
${ }^{1}$ Nonparametric Wilcoxon signed-rank test and nonparametric McNemar/Bowker test were used to assess the measures of Aerobika OPEP vs. standard-of-care users. significant difference declared at $p<0.05$

${ }^{2}$ The entire length of stay of a rehospitalizations was included in the analysis if the admission date was within 30 days following the discharge date of the index hospitalization
}

condition, Tse et al. [98] reported an economic analysis of OPEP therapy comparing real-world resource use and disease exacerbation among US-based patients with COPD or chronic bronchitis who had been prescribed either of two commonly used OPEP devices (Acapella* (any version, $n=1857$ patients) or Aerobika* $(n=619$ patients)). Several of their outcome measures showed significant differences between the two OPEP devices (bold rows in Table 8). After 
Table 8 Post-discharge severe exacerbations and all-cause post-discharge healthcare resource usage (HRU) in the 12-month follow-up period in the matched cohorts of COPD/chronic bronchitis patients (from Tse et al. [98]) [Original article created under the terms of the Creative Commons Attribution-Non-Commercial 4.0 international license (http:// creativecommons.org/licenses/by-nc/4.0/: used by permission of the authors]

\begin{tabular}{|c|c|c|c|c|c|}
\hline Severity & $\begin{array}{l}\text { Time post } \\
\text { hospital discharge }\end{array}$ & Measure & $\begin{array}{l}\text { Acapella* OPEP } \\
\text { device therapy }\end{array}$ & $\begin{array}{l}\text { Aerobika* OPEP } \\
\text { device therapy }\end{array}$ & $p$ value $^{1}$ \\
\hline \multirow[t]{6}{*}{ Severe $^{1}$} & \multirow{2}{*}{$\begin{array}{l}\text { 30-day post- } \\
\text { discharge }^{2}\end{array}$} & $\geq 1$ severe exacerbation, $n(\%)$ & $306(17.4)$ & $68(12.0)$ & 0.001 \\
\hline & & $\begin{array}{l}\text { Number of severe exacerbations per patient } \\
\quad(\text { mean } \pm \text { SD })\end{array}$ & $0.2 \pm 0.5$ & $0.1 \pm 0.4$ & 0.002 \\
\hline & \multirow{4}{*}{$\begin{array}{l}\text { 12-month post- } \\
\text { discharge }\end{array}$} & $\geq 1$ severe exacerbation, $n(\%)$ & $841(45.3)$ & $245(39.6)$ & 0.01 \\
\hline & & $\begin{array}{l}\text { Length of stay per stay per patient among patients } \\
\text { with } \geq 1 \text { hospitalization (mean } \pm S D)\end{array}$ & $7.1 \pm 5.4$ & $6.5 \pm 3.9$ & 0.05 \\
\hline & & $\begin{array}{l}\text { Number of severe exacerbations per patient } \\
\text { per year (mean } \pm S D)\end{array}$ & $0.9 \pm 1.4$ & $0.7 \pm 1.3$ & 0.01 \\
\hline & & $\begin{array}{l}\text { Time to severe exacerbation in days } \\
\quad(\text { mean } \pm \mathrm{SD})\end{array}$ & $96.6 \pm 97.8$ & $102.0 \pm 97.5$ & 0.44 \\
\hline \multirow[t]{4}{*}{ Moderate } & \multirow{2}{*}{$\begin{array}{l}\text { 30-day post- } \\
\text { discharge }^{2}\end{array}$} & $\geq 1$ moderate exacerbation, $n(\%)$ & $245(13.2)$ & $76(12.3)$ & 0.58 \\
\hline & & $\begin{array}{l}\text { Number of moderate exacerbations per patient } \\
\quad(\text { mean } \pm S D)\end{array}$ & $0.2 \pm 0.6$ & $0.2 \pm 0.5$ & 0.37 \\
\hline & \multirow{2}{*}{$\begin{array}{l}\text { 12-month post- } \\
\text { discharge }\end{array}$} & $\geq 1$ moderate exacerbation, $n(\%)$ & $254(41.0)$ & $762(41.0)$ & 0.98 \\
\hline & & $\begin{array}{l}\text { Number of moderate exacerbations per patient } \\
\text { per year (mean } \pm S D)\end{array}$ & $1.2 \pm 3.2$ & $1.0 \pm 1.8$ & 0.03 \\
\hline \multirow{9}{*}{$\begin{array}{l}\text { All Cause HRU: } \\
\text { In-patient visits }\end{array}$} & \multirow{2}{*}{$\begin{array}{l}\text { 30-day post- } \\
\text { discharge }^{2}\end{array}$} & Patients with $\geq 1$ early readmission ${ }^{2}$ & $358(20.3)$ & $79(13.9)$ & $<0.001$ \\
\hline & & $\begin{array}{l}\text { Number of early readmissions per patient } \\
\quad(\text { mean } \pm \text { SD })\end{array}$ & $0.24 \pm 0.5$ & $0.16 \pm 0.4$ & 0.001 \\
\hline & \multirow{3}{*}{$\begin{array}{l}\text { 12-month post- } \\
\text { discharge }\end{array}$} & Patients with $\geq 1$ in patient visit, $n(\%)$ & $962(51.8)$ & $278(44.9)$ & 0.003 \\
\hline & & $\begin{array}{l}\text { Length of stay per stay per patient among patients } \\
\text { with } \geq 1 \text { in patient visit, mean }(\mathrm{SD})\end{array}$ & $8.3 \pm 7.2$ & $7.5 \pm 4.9$ & 0.28 \\
\hline & & $\begin{array}{l}\text { Number of in-patient visits per patient per } \\
\text { year (mean } \pm \text { SD) }\end{array}$ & $1.1 \pm 1.6$ & $0.9 \pm 1.4$ & 0.003 \\
\hline & \multirow[t]{2}{*}{ ED visits } & Patients with $\geq 1$ in patient visit, $n(\%)$ & $1113(59.9)$ & $381(61.6)$ & 0.45 \\
\hline & & $\begin{array}{l}\text { Number of in-patient visits per patient per year } \\
\quad(\text { mean } \pm S D)\end{array}$ & $1.9 \pm 4.4$ & $1.8 \pm 2.5$ & 0.52 \\
\hline & \multirow{2}{*}{$\begin{array}{l}\text { Outpatient/ } \\
\text { physician's } \\
\text { office visits }\end{array}$} & Patients with $\geq 1$ in patient visit, $n$ (\%) & $1739(93.6)$ & $575(92.9)$ & 0.50 \\
\hline & & $\begin{array}{l}\text { Number of in-patient visits per patient per year } \\
\quad(\text { mean } \pm \mathrm{SD})\end{array}$ & $21.2 \pm 22.1$ & $20.5 \pm 22.5$ & 0.51 \\
\hline
\end{tabular}

Data in bold font indicate statistical significance criterion $(p=0.05)$ met

${ }^{1}$ Severe exacerbation was defined as an inpatient admission with COPD or chronic bronchitis diagnosis, anytime during the follow-up period, not including the index visit

${ }^{2}$ In patient admission within 30 days following index hospitalization discharge date, assessed among patients with index inpatient visit $(\mathrm{n}=568$ Aerobika* device users and $n=1762^{*}$ Acapella users) 
discharge from the index visit, Aerobika* device users were less likely to have $\geq 1$ severe exacerbation within 30 days $(12.0 \%$ vs. $17.4 \%$, $p=0.01)$ and/or at 12 months post discharge (39.6\% vs. $45.3 \%, p=0.01)$. They also experienced fewer 12-month severe exacerbations (mean, 0.7 vs. 0.9 per patient per year, $p=0.01$ ), with significantly longer time to first severe exacerbation than experienced by the Acapella* device users (log-rank $p=0.01)$. They also reported that Aerobika* device users were also less likely to have $\geq 1$ all cause in-patient visit within 30 days ( $13.9 \%$ vs. $20.3 \%, p<0.001)$ and 12 months $(44.9 \%$ vs. $51.8 \%, p=0.003)$ than experienced by the Acapella* device users. Although they did not link the differences in outcomes between the two devices to one or more specific mechanical performance measures, they concluded that OPEP devices may vary in clinical effectiveness, and that the Aerobika* OPEP device (in particular) may be a beneficial add-on to usual care for these patients.

Thanh et al. [99] undertook a further economic-based assessment limited to the Canadian experience, by investigating the costeffectiveness using a Markov model [100] to interpret data from the Alberta healthcare system for a representative OPEP device (Aerobika* $^{*}$ compared with those not using the device (controls) in the management of COPD with patients who had recently experienced an exacerbation. Their model inputs involved a series of plausible clinical scenarios, such as the probability of an exacerbation within several different time periods and included economic consequences. They found that the economic outcome resulting from using the OPEP device was the dominant variable (probability $=72 \%$ ), as the result of this therapy being more effective and less costly. Overall, after one year (the scope of the study), their model predicted a patient using this device would save \$694 in healthcare costs and acquire 0.04 more in quality adjusted life years (QALYs), in comparison with the equivalent situation without OPEP therapy. If an assumption was made that the willingness to pay (WTP) threshold is $\$ 50,000$ per QALY gained, the probability for the Aerobika* device being cost-effective was found to be $77 \%$. A limitation of this analysis is the use of just US hospital-based data relating to effectiveness, on which their model was based, as these hospitals are penalized for patient readmission within a 30-day period. Currently, this constraint does not exist in Canada or elsewhere to the authors' knowledge, so that more research is needed to confirm the cost-effectiveness of OPEP therapy outside of the US. Nevertheless, given that one of the major treatment goals in the GOLD guidelines is to minimize exacerbations and prevent re-exacerbations [73], OPEP therapy should be viewed as a potential component of a treatment strategy to improve symptom control and reduce the risk of re-exacerbations in patients with COPD.

The excessive or inappropriate use of medications, in particular oral corticosteroids (OCS) to control inflammatory disease and antibiotics to mitigate infection, is an undesirable outcome of therapy to treat chronic obstructive conditions such as bronchiectasis and chronic bronchitis [101, 102]. Both are associated with inflammation and excessive mucus secretions. The findings from the clinical studies just reviewed point to the possibility that a nondrug-based alternative therapy exists for these patients. However, confirmatory research is still needed, involving randomized controlled trials with larger patient numbers [89, 103] ideally involving a wide spectrum of disease severity.

\section{EXTENDING THERAPY FOR BRONCHIAL HYGIENE THROUGH THE COMPLETE BREATHING CYCLE}

\section{OPEP-Nebulizer Therapy}

The treatment of obstructive pulmonary diseases by inhaled medications is well established [104-108]. However, it is self-evident that airway patency is a necessary precondition before such medications can reach the receptors to provide therapeutic benefits. The combination of inhaled medication delivery with PEP has been established for some time [109, 110]. However, recently, with the increased variety of 
OPEP devices becoming available, there has been increasing interest in exploring the potential for combining OPEP with inhaled medication therapy, delivered principally by a nebulizer [19, 110, 111].

In a laboratory study, Berlinski simulated concomitant patient use of OPEP devices (Acapella* Choice and Duet) with continuously operating jet nebulizers by re-creating inhalation-exhalation patterns for a child, small adult, and large adult by simulator [111]. He reported that, when evaluating Up-Draft II Opti-Neb nebulizer (Hudson-RCI) with these OPEP devices, significant particle size selectivity occurred, arising within the OPEP device. This process resulted in preferential removal of the larger droplets containing albuterol (salbutamol) emitted from the nebulizer-on-test, likely as the result of a combination of inertial impaction and turbulent deposition. These droplets retained by the OPEP device contained the bulk of the medication. The mass median aerodynamic diameter (MMAD), which represents the measure of central tendency of the droplet distribution of the aerosol ex OPEP device, therefore decreased from 4.13 to $1.24 \mu \mathrm{m}$ with this nebulizer when combined with the Acapella* Choice OPEP device. This reduction in droplet size was associated with a decrease of $76 \%$ in the mass of drug delivered for the patient to inhale. Similar findings were obtained with the Acapella* Duet OPEP device when used with the same nebulizer. However, this size reduction did not occur when a LC-Plus* (PARI Respiratory Equipment) nebulizer was used with the same manufacturer's PEP device (PARI PEP*), the droplet MMAD ex OPEP device remaining between 3.42 and $3.45 \mu \mathrm{m}$ compared with $3.42 \pm 0.15 \mu \mathrm{m}$ delivered from the nebulizer directly. Berlinski [111] concluded that sites where aerosol deposition can occur during transfer to the PEP device were avoided with this PEP therapy-nebulizer combination. The PARI PEP system replaces the nebulizer inspiratory valve of the LC Plus nebulizer, and it is used with a mouthpiece, without exhalation valve. Berlinski also noted that this finding is consistent with the outcome from another laboratory study by Mitchell et al. [112], who observed that OPEP devices that avoid restriction of the aerosol pathway (in their case, within the Aerobika* device) do not significantly alter the dose available for inhalation. Looking at evidence from direct measures of drug deposition in the lungs of patients, the large losses of medication in the Acapella* - Up-Draft II Opti-Neb nebulizer arm of the Berlinski study [111] are consistent with the findings from a scintigraphic study with healthy volunteer adults, undertaken by Mesquita et al. [110]. This group found that placing a jet nebulizer (ST3, NS, São Paulo, Brazil) distal to an Acapella* Choice OPEP device, as recommended by the manufacturer at that time, substantially decreased intrapulmonary deposition. Importantly, however, these authors qualified their observation by commenting that repositioning the jet nebulizer proximally to the Acapella* Choice device improved medication delivery by avoiding losses within the OPEP device.

The combination of a breath-actuated (BA) jet nebulizer located in combination proximally to an OPEP device (Aerobika* with AeroEclipse*II BA nebulizer, Fig. 9A) was developed with the goal of optimizing therapy by avoiding waste of medication during the exhalation portion of each breathing cycle [112]. In addition to the minimization of drug deposition within the OPEP device, a further advantage is a reduction in fugitive emissions [113], important in the context of protecting nearby health care providers from inhaling drug or pathogens [114]. The inhalation pathway through this combination (Fig. 9B) is directly from the nebulizer mouthpiece via the connecting transfer tube of the OPEP component, in which a one-way valve is open, thereby avoiding aerosol deposition within this additional tubing. Towards the end of each inhalation, aerosol emission from the BA nebulizer ceases, and upon initiation of exhalation, the one-way valve in the transfer tube closes, diverting flow via the OPEP system. Mitchell et al. [112] showed that the additional pathway for the nebulizer-generated aerosol droplet stream had only a minimal influence on the resulting aerodynamic particle size distribution of a $250 \mu \mathrm{g} / \mathrm{ml}$ budesonide suspension aerosol measured by a cascade impactor sampling from the mouthpiece of the Aerobika* OPEP device component of the combination 
( $n=9$ replicates) as shown in Fig. 9C. Values of fine particle mass $<5.4 \mu \mathrm{m}$ aerodynamic diameter likely to penetrate to receptors in the airways of the lungs involved with asthma or COPD (mean \pm SD) were only marginally different at $250 \pm 21 \mu \mathrm{g}$ and $278 \pm 8 \mu \mathrm{g}$ (paired $t$ test, $p=0.043$ ) via the OPEP component and directly from the BA nebulizer, respectively. Similar outcomes were also obtained for two solution medications $(833 \mu \mathrm{g} / \mathrm{ml}$ albuterol sulfate $(1042 \pm 43 \mu \mathrm{g}$ via OPEP component; $1004 \pm 70 \mu \mathrm{g}$ direct) and $250 \mu \mathrm{g} / \mathrm{ml}$ ipratropium bromide $(426 \pm 27 \mu \mathrm{g}$ via OPEP component; $452 \pm 28 \mu \mathrm{g}$ direct $(p>0.38)$.

\section{FUTURE DIRECTIONS FOR SMALL DEVICE-DELIVERED OPEP}

There are currently three new developments that act as pointers to how the therapy may develop soon. These are:

1. OPEP combined with Positive Airway Pressure (OPEP-PAP),

2. Single patient disposable OPEP devices,

3. So-called 'smart' OPEP devices.

The first OPEP combined with PAP system, based on the Aerobika* OPEP device used in series with the VersaPAP* attachment (Trudell Medical International/Monaghan Medical Corp., (Fig. 10)), creates airway expansion on inhalation, allowing for the patient to take in a larger volume breath. The device operates by augmenting the input flow of oxygen or air such that positive pressure is maintained throughout the entire breathing cycle. On exhalation, the additional air volume enables a longer duration to improve airway clearance and further lung expansion by the added flow resistance of both devices.

Currently, there are no smart OPEP devices commercially available, although at least one patent application describes the generation of an input signal correlated to the flow or pressure, a processor operative to receive the input signal from the input component and generate an output signal, and an output component operative to receive the output signal and display an output [115]. Given the present concerns regarding patient adherence to therapy in COPD [116], and especially with the complex regimen associated with CF management [117], the likelihood of growth in the appearance of such technology is strong, with potential benefits for both patient and clinician.

\section{CONCLUSIONS}

The growing availability of the increasing range of OPEP devices, each with their own attributes and limited outcome data across the range of devices, makes it confusing for the clinician to understand device selection and optimum therapy for each patient based on the symptoms

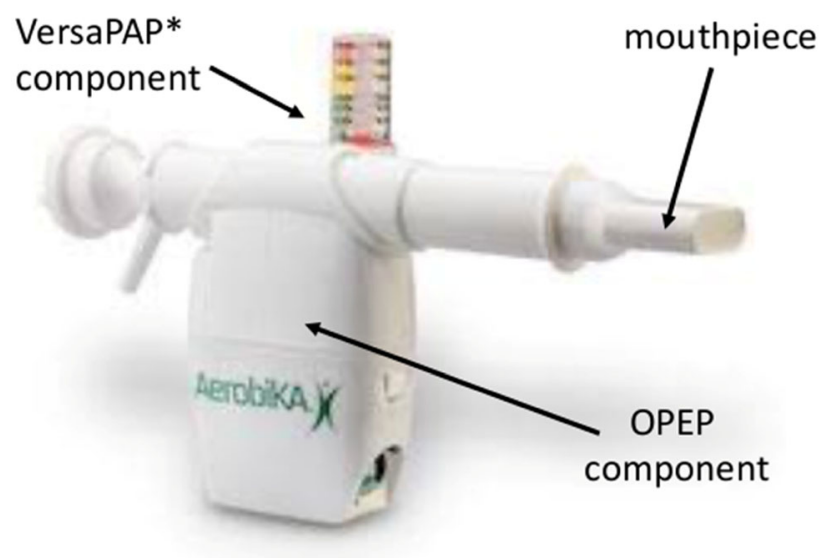

Fig. 10 Aerobika* OPEP device with VersaPAP* attachment 
as well as the disease condition. Furthermore, the development of OPEP as a recognized ACT has been frustrated by wide differences in pathology associated with the variety of diseases for which this therapy has been used, as well as the small scale (low patient numbers) and duration of clinical trials [66] that have made it difficult to obtain strong signals in terms of mechanism of action and resulting improvement in lung function [66]. In particular, Morrison and Milroy, in their systematic review of OPEP therapy for patients with CF, have counselled that larger and longer duration trials are needed to measure the frequency of lung infections, preference, adherence to and general satisfaction with treatment [66]. Encouragingly, in 2019, Bourbeau et al. [89] commented that although the number of large, controlled clinical studies investigating OPEP devices is still small (and this situation is reflected in the lack of visibility in many clinical guidelines), there is a growing body of evidence supporting the effectiveness of some OPEP devices in specific patient populations. Importantly, however, there is an increasing body of evidence that OPEP therapy enhances mobilization of mucus secretions in the various disease modalities for which these devices have been applied [23, 88, 118, 119]. This finding is important because pathogen infection exacerbated by mucus in situ in the airways of the lungs is a major cause of hospitalization in these patients [120-122]. Bourbeau et al. [89] have also commented that the range of OPEP devices available operate differently, produce different pressure pulse waveforms, as well as diverging in terms of usability and cleaning. These devices therefore do not all provide the same benefits to patients and may not be interchangeable, a situation that this present overview has also highlighted. It is therefore important that clinicians prescribing these devices base their judgement on the published clinical evidence of efficacy. Further, patient selection along with proper instruction of how to use the device optimally, including performing effective huffcoughs [123-125] is important to optimize therapeutic effect. Finally, this review has highlighted that clinical investigations have thus far been focused on patients with COPD/ chronic bronchitis. There is therefore an unmet need to include the much smaller cohort of patients with CF, whose need for better mucus clearance therapies is at least as great. Such approaches would potentially be of higher value in CF than in COPD due to the particularities of the mucus generation in the former condition, in particular it's extremely high viscosity, as well as the consequent enhanced difficulty of mobilization of impacted plugs and deposits in the airways.

The present overview, by highlighting significant developments both in device attributes and performance, including key clinical evaluations, provides insight into how OPEP-based therapies in the future may fit more extensively into the spectrum of ACTs available to the clinician for the management of lung airway diseases involving chronic mucus secretion production.

\section{TRADEMARKS}

The symbol '*' has been used to represent a manufacturer's registered or unregistered trademark.

\section{ACKNOWLEDGEMENTS}

The authors thank Ms. Chris Patrick (Trudell Medical International) for her advice during the preparation of this review.

Funding. Funding for the preparation of this review was provided to JPM by Monaghan Medical Corporation. No Rapid Service Fee was received by the journal for the publication of this article.

Authorship. All named authors meet the International Committee of Medical Journal Editors (ICMJE) criteria for authorship for this article, take responsibility for the integrity of the work as a whole, and have given their approval for this version to be published.

Author Contributions. JM and JS wrote the text and assembled the tables and figures, DC 
and JAS provided critical oversight throughout the preparation of the article, including the identification of additional sources of pertinent studies. No assistance was provided by a professional medical writer.

Disclosures. Dominic P. Coppolo and Judy Schloss are employees of Monaghan Medical Corporation (MMC) who market the Aerobika* OPEP device and the AeroEclipse*-II BA nebulizer in the US and Mexico; Jason A. Suggett is an employee of Trudell Medical International, manufacturer of both devices and distributor worldwide, except for the US and Mexico; Jolyon P. Mitchell is a private consultant who has received funding from TMI and MMC.

Compliance with Ethics Guidelines. This article is based on previously conducted studies and does not contain any new studies with human participants or animals performed by any of the authors.

Open Access. This article is licensed under a Creative Commons Attribution-NonCommercial 4.0 International License, which permits any non-commercial use, sharing, adaptation, distribution and reproduction in any medium or format, as long as you give appropriate credit to the original author(s) and the source, provide a link to the Creative Commons licence, and indicate if changes were made. The images or other third party material in this article are included in the article's Creative Commons licence, unless indicated otherwise in a credit line to the material. If material is not included in the article's Creative Commons licence and your intended use is not permitted by statutory regulation or exceeds the permitted use, you will need to obtain permission directly from the copyright holder. To view a copy of this licence, visit http:// creativecommons.org/licenses/by-nc/4.0/.

\section{REFERENCES}

1. Antunes MB, Cohen NA. Mucociliary clearance: a critical upper airway host defense mechanism and methods of assessment. Curr Opin Allergy Clinical Immunol. 2007;7(1):5-10.

2. Bustamante-Marin XM, Ostrowski LE. Cilia and mucociliary clearance. Cold Spring Harb Perspect Biol. 2017;9:028241.

3. Ohar JA, Donohue JF, Spangenthal S. The role of guaifenesin in the management of chronic mucus hypersecretion associated with stable chronic bronchitis: a comprehensive review. Chron Obs Pulmon Dis. 2019;6(4):341-9.

4. Yaghi A, Dolovich MB. Airway epithelial cell cilia and obstructive lung disease. Cells. 2016;5:40.

5. Braiman A, Priel Z. Efficient mucociliary transport relies on efficient regulation of ciliary beating. Respir Physiol Neurobiol. 2008;163:202-7.

6. Button B, Boucher RC, University of North Carolina Virtual Lung Group. Role of mechanical stress in regulating airway surface hydration and mucus clearance rates. Respir Physiol Neurobiol. 2008;163: 189-201.

7. Randell SH, Boucher RC. Effective mucus clearance is essential for respiratory health. Am J Respir Cell Mol Biol. 2006;35:20-8.

8. Lewis B, Patial S. Immunopathology of airway surface liquid dehydration disease. J Immunol Res. 2019;2019:1-16.

9. Donaldson SH, Boucher RC. Sodium channels and cystic fibrosis. Chest. 2007;132(5):1631-6.

10. Mall MA. Unplugging mucus in cystic fibrosis and chronic obstructive pulmonary disease. Ann Am Thorac Soc. 2016;13(Suppl. 2):S177-85.

11. Prescott E, Lange P, Vestbo J. Chronic mucus hypersecretion in COPD and death from pulmonary infection. Eur Respir J. 1995;8:1333-8.

12. Burgel PR, Nadel JA. Epidermal growth factor receptor-mediated innate immune responses and their roles in airway diseases. Eur Respir J. 2008;32: 1068-81.

13. Burgel PR, Martin C. Mucus hypersecretion in COPD: Should we only rely on symptoms? Eur Respir Rev. 2010;19(116):94-6.

14. Lin VY, Kaza N, Birket SE, et al. Excess mucus viscosity and airway dehydration impact COPD airway clearance. Eur Respir J. 2020;55:1900419.

15. Smith M. Diagnosis and management of bronchiectasis. CMAJ. 2017;189:E828-35. 
16. Jasper AE, McIver WJ, Sapey E, et al. Understanding the role of neutrophils in chronic inflammatory airway disease. F1000 Research. 2019;8:557.

17. Evans CM, Kim K, Tuvim MJ. Mucus hypersecretion in asthma: Causes and effects. Curr Opin Pulm Med. 2009; 15(1):4-11.

18. Volsko TA. Airway clearance therapy: finding the evidence. Respir Care. 2013;58(10):1669-78.

19. Rubin BK. Aerosol medications for the treatment of mucus clearance disorders. Respir Care. 2015;16(6): 825-32.

20. McCool F, Rosen MJ. Nonpharmacologic airway clearance therapies: ACCP Evidence-based clinical practice guidelines. Chest. 2006;129:250-9.

21. Holland AE, Button BM. Is there a role for airway clearance techniques in chronic obstructive pulmonary disease? Chron Respir Dis. 2006;3:83-91.

22. McIlwaine M, Bradley J, Elborn JS, et al. Personalising airway clearance in chronic lung disease. Eur Respir Rev. 2017;26:160086.

23. Button BM, Button B. Structure and function of the mucus clearance of the lung. Cold Spring Harb Perspect Med. 2013;3(8):009720.

24. Pryor JA, Tannenbaum E, Scott SF. Beyond postural drainage and percussion: airway clearance in people with cystic fibrosis. J Cystic Fibrosis. 2010;9:187-92.

25. Ontario Ministry of Health and Long-Term Care Medical Advisory Secretariat. Airway clearance devices for cystic fibrosis. Ontario Health Technology Assessment Series 2009; 9(26):1-50. Available at: https://www.hqontario.ca/Portals/0/ Documents/evidence/reports/rev_airway_ 20091201.pdf, visited August 6, 2021.

26. Chatwin M. How to use a mechanical insufflator-exsufflator "cough assist machine." Breathe. 2008;4(4):321-5.

27. Goncavles MR, Winck JC. Commentary: Exploring the potential of mechanical insufflation-exsufflation. Breathe. 2008;4(4):326-9.

28. Nava S, Barbarito N, Piaggi G, et al. Physiological response to intrapulmonary percussive ventilation in stable COPD patients. Respir Med. 2006;100: 1526-33.

29. Touissant M, Guillet M-C, Paternotte S, et al. Intrapulmonary effects of setting parameters in portable intrapulmonary percussive ventilation devices. Respir Care. 2012;57(5):735-42.
30. Toussaint M, De Win H, Steens $M$, et al. Effect of intrapulmonary percussive ventilation on mucus clearance in Duchenne muscular dystrophy patients: a preliminary report. Respir Care. 2003;48(10):940-7.

31. Riffard G, Buzenet J, Guérin C. Intrapulmonary percussive ventilation superimposed on conventional mechanical ventilation: Comparison of volume controlled and pressure-controlled modes. Respir Care. 2014;59(7):1116-22.

32. Dosman C, Jones R. High-frequency chest compression: a summary of the literature. Can Respir J. 2005;12(1):37-41.

33. Barto TL, Marcelli DJ, Daignault S, et al. Real-life experience with high-frequency chest wall oscillation vest therapy in adults with non-cystic fibrosis bronchiectasis. Ther Adv Respir Dis. 2020;14:1-11.

34. Cantin AM, Bacon M, Berthiaune Y. Mechanical airway clearance using the Frequencer electroacoustical transducer in cystic fibrosis. Clin Invest Med. 2006;29(3):159-65.

35. Cantin A, Bacon M. Mechanical clearance of human airways using the Frequencer electro-acoustical transducer - a white paper. Dymedso Inc. 2020. Available at: www.dymedso.com , White_paper_ rev0_Sept20_041 (visited August 5, 2021).

36. Benoit CM, Christensen E, Nickel AJ, et al. Objective measures of Vest therapy adherence among pediatric subjects with cystic fibrosis. Respir Care. 2020;65(12):1831-7.

37. Demchuk AM, Chatburn RL. Performance characteristics of positive expiratory pressure devices. Respir Care. 2021;66(3):482-93.

38. AARC Clinical Practice Guideline. Use of positive airway pressure adjuncts to bronchial hygiene therapy. Respir Care. 1993;38(5):516-21.

39. Christensen EF, Jensen RH, Schønemann NK, et al. Flow dependent properties of positive expiratory pressure devices. Monaldi Arch Chest Dis. 1995;50(2):150-3.

40. Mcllwaine PM, Wong LT, Peacock D, et al. Longterm comparative trial of positive expiratory pressure versus oscillating positive expiratory pressure (flutter) physiotherapy in the treatment of cystic fibrosis. J Pediatr. 2001;138:845-50.

41. Olsén MF, Olofsson P, Frejd P, et al. Technical aspects of devices and equipment for positive expiratory pressure with and without oscillation. Respir Care. 2021;66(5):862-77. 
42. Myers TR. Positive expiratory pressure and oscillatory positive expiratory pressure therapies. Respir Care. 2007;52(10):1308-26.

43. Andersen J, Qvist J, Kann T. Recruiting collapsed lung through collateral channels with positive expiratory pressure. Scand J Respir Dis. 1979;60: 260-6.

44. Tonnesen P, Stovring S. Positive expiratory pressure (PEP) as lung physiotherapy in cystic fibrosis: a pilot study. Eur J Respir Dis. 1984;65:419-22.

45. Hofmeyer JL, Webber BA, Hodson ME. Evaluation of positive expiratory pressure as an adjunct to chest physiotherapy in the treatment of cystic fibrosis. Thorax. 1986;41:951-4.

46. Steen HJ, Redmond AOB, O'Neill D, et al. Evaluation of the PEP mask in cystic fibrosis. Acta Pediatr Scand. 1991;80:51-4.

47. McIlwaine PM, Wong LTK, Peacock D, et al. Longterm comparative trial of conventional postural drainage and percussion versus positive expiratory pressure physiotherapy in the treatment of cystic fibrosis. J Pediatr. 1997;131:570-3.

48. McIlwaine PM, Button B, Dwan K. Positive expiratory pressure physiotherapy for airway clearance in people with cystic fibrosis (Review). Cochrane Database Syst Rev. 2015. https://doi.org/10.1002/ 14651858.CD003147.pub5.

49. Andrews J, Sathe NA, Krishnaswami S, et al. Nonpharmacologic airway clearance technique $s$ in hospitalized patients: a systematic review. Respir Care. 2013;58(12):2160-6.

50. Van Fleet H, Dunn DK, McNinch ML, et al. Evaluation of functional characteristics of 4 oscillatory positive pressure devices in a simulated cystic fibrosis model. Respir Care. 2017;62(4):451-8.

51. App EM, Kieselmann R, Reinhardt D, et al. Sputum rheology changes in cystic fibrosis lung disease following two different types of physiotherapy: flutter vs autogenic drainage. Chest. 1998;114(1):171-7.

52. Tambascio J, de Souza L, Lisboa R, et al. The influence of Flutter VRP1 components on mucus transport of patients with bronchiectasis. Respir Med. 2011;105:1316-21.

53. Chang HK, Weber ME, King M. Mucus transport by high-frequency nonsymmetrical oscillatory airflow. J Appl Physiol. 1988;65(3):1203-9.

54. Poncin W, Reychler G, Liistro M, et al. Comparison of 6 oscillatory positive expiratory pressure devices during active expiratory flow. Respir Care. 2020;65(4):492-9.
55. Chilvers M, Rutman A, O'Callaghan C. Functional analysis of cilia and ciliated epithelial ultrastructure in healthy children and young adults. Thorax. 2003;58:333-8.

56. Patterson J, Hewitt O, Kent L, et al. Acapella ${ }^{\circledR}$ versus usual airway clearance during acute exacerbation in bronchiectasis: a randomized crossover trial. Chron Respir Dis. 2007;4(2):67-74.

57. Miller MR, Pedersen OF. Peak flowmeter resistance decreases peak expiratory flow in subjects with COPD. J Appl Physiol. 2000;89:283-90.

58. Volsko TA, DiFiore J, Chatburn RL. Performance comparison of two oscillating positive expiratory pressure devices: acapella versus flutter. Respir Care. 2003;48(2):124-30.

59. Morrison L, Innes S. Oscillating devices for airway clearance in people with cystic fibrosis. Cochrane Database Syst Rev. 2017;5:CD006842.

60. Nicholson C, Lee A. Bronchiectasis Toolbox: Oscillating positive expiratory pressure therapy. 2021. https://bronchiectasis.com.au/physiotherapy/ techniques/oscillating-positive-expiratory-pressuretherapy, visited August 5, 2021.

61. Fujita A, Murata K, Takamori M. Novel method for sputum induction using the Lung Flute in patients with suspected pulmonary tuberculosis. Respirology. 2009;14(6):899-902.

62. Sethi S, Yin J, Anderson PK. Lung flute improves symptoms and health status in COPD with chronic bronchitis: a 26 week randomized controlled trial. Clin Translat Med. 2014;3:29.

63. Cegla UH. Physiotherapy with oscillating PEP systems (RC-Cornet, VRP1 in COPD). Pneumologie. 2000;54:440-6.

64. Mercury Medical. ShurClear* oscillating positive expiratory pressure device: Instructions for use. 2020. Available at: https://www.mercurymed.com/ product/airway-clearance-devices/, visited August 5, 2021.

65. Westmed Inc. Vibralung* acoustical percussor: Online manual for healthcare professionals. 2014. Available at: http://westmedinc.com/vibralung/, visited August 6, 2021.

66. Morrison L, Milroy S. Oscillating devices for airway clearance in people with cystic fibrosis. Cochrane Database Syst Rev. 2020. https://doi.org/10.1002/ 14651858.CD006842.pub4.

67. Wheatley CM, Baker SE, Daines C, et al. Influence of the VibraLung device on pulmonary function and 
sputum expectoration in patients with cystic fibrosis. Pediatr Pulmonol. 2013;48(Suppl 36):357.

68. Medical Holdings LLC. VibraPEP* oscillatory PEP device: Instructions for use. 2020. Available at: https://www.vibrapep.com/wp-content/uploads/ 2018/04/IFU-MEDICA-44F50-44F10-01072018.pdf , visited August 5, 2021.

69. Goodell HP, Shenoy SK, Shenkute NT, et al. Adhesive and cohesive peel force measurement of human airway mucus. BioProtocol LLC. 2019;9(13):e3287.

70. Anastasio F, Barbuto F, Scamechcia E, et al. Medium-term impact of COVID-19 on pulmonary function, functional capacity and quality of life. Eur Respir J. 2021;58:2004035.

71. Flude L, Agent P, Bilton D. Chest physiotherapy techniques in bronchiectasis. Clin Chest Med. 2012;33:351-61.

72. Womersley JR. Method for the calculation of velocity, rate of flow and viscous drag in arteries when the pressure gradient is known. J Physiol. 1955;127(3):553-63.

73. Global Initiative for Chronic Obstructive Lung Disease Inc. Global strategy for the diagnosis, management and prevention of chronic obstructive pulmonary disease: 2021 Report. Available at: https://goldcopd.org/wp-content/uploads/2020/11/ GOLD-REPORT-2021-v1.1-25Nov20_WMV.pdf ， visited August 5, 2021.

74. Hart N, Polkey MI, Clément A, et al. Changes in pulmonary mechanics with increasing disease severity in children and young adults with cystic fibrosis. Am J Respir Crit Care Med. 2002;166(1): 61-6.

75. Webber BA, Pryor JA, Bethune DD, et al. Physiotherapy techniques. In: Pryor JA, Webber BA, editors., et al., Physiotherapy for respiratory and cardiac problems. London: Churchill Livingstone; 1998. p. 137-210.

76. Pryor JA. Physiotherapy for airway clearance in adults. Eur Respir J. 1999;14:1418-24.

77. Svenningson S, Paulin GP, Sheikh K, et al. Oscillatory positive expiratory pressure in chronic obstructive pulmonary disease. J Chron Obstruct Pulmon Dis. 2016;13(1):66-74.

78. Van Beek EJR, Wild JM, Kauczor H-U, et al. Functional MRI of the lung using hyperpolarized 3-helium gas. J Magn Reson Imaging. 2004;20(4): 540-54.

79. Fain S, Schiebler ML, McCormack DG. Imaging of lung function using hyperpolarized helium-3 magnetic resonance imaging: Review of current and emerging translational methods and applications. J Magn Reson Imaging. 2010;32(6):1398-408.

80. Kirby M, Heydarian M, Svenningsen S, et al. Hyperpolarized $3 \mathrm{He}$ magnetic resonance functional imaging semiautomated segmentation. Acad Radiol. 2012;19(2):141-52.

81. Fahy JV, Dickey BF. Airway mucus function and dysfunction. N Engl J Med. 2010;363(23):2233-47.

82. Cone RA. Barrier properties of mucus. Adv Drug Deliv Rev. 2009;61:75-85.

83. Lauwers E, Ides K, van Hoorenbeeck K, et al. Outcome measures for airway clearance techniques in children with chronic obstructive lung diseases: A systematic review. Respir Res. 2020;21:217.

84. Milan S, Bondalapati P, Megally M, et al. Positive expiratory pressure therapy with and without oscillation and hospital length of stay for acute exacerbation of chronic obstructive pulmonary disease. Int J COPD. 2019;14:2553-61.

85. Svenningson S, Guo F, McCormack DG, et al. Noncystic fibrosis bronchiectasis: Regional abnormalities and response to airway clearance therapy using pulmonary functional magnetic resonance imaging. Acad Radiol. 2017;24(1):4-12.

86. US Food and Drug Administration. Premarket approval (PMA). Silver Spring, MD, USA. 2019 available at: https://www.fda.gov/medical-devices/ premarket-submissions/premarket-approval-pma visited Oct 52021.

87. Rubin BK. Designing clinical trials to evaluate mucus clearance therapy. Respir Care. 2007;52(10): 1348-58.

88. Alghamdi SM, Barker RE, Alsulayyaim ASS. Use of oscillatory positive expiratory pressure (OPEP) devices to augment sputum clearance in COPD: a systematic review and meta-analysis. Thorax. 2020;75(10):855-63.

89. Bourbeau J, McIvor RA, Devlin HM, et al. Oscillating positive expiratory pressure (OPEP) device therapy in Canadian respiratory disease management: Review, care gaps and suggestion for use. Can J Resp Crit Care Sleep Med. 2019;3(4):233-40.

90. Shabari VP, Alaparthi GP, Vishakacharya V. Comparison of Acapella and RC-Cornet for airway clearance in bronchiectasis: a pilot study. Int J Curr Res Rev. 2011;11(3):138-48.

91. Valente AM, Gastaldi AC, Cravo SL. The effect of two techniques on the characteristics and transport 
of sputum in patients with bronchiectasis: a pilot study. Physiotherapy. 2004;90(3):158-64.

92. Woods JA, Wheeler JS, Finch CK, et al. Corticosteroids in the treatment of acute exacerbations of chronic obstructive pulmonary disease. Int J COPD. 2014;9:421-30.

93. Carvalho CR, Paisani DM, Lunardi AC. Incentive spirometry in major surgeries: a systematic review. Braz J Phys Ther. 2011;15(5):343-50.

94. Agostini P, Cieslik H, Rathinam S, et al. Postoperative pulmonary complications following thoracic surgery: are there any modifiable risk factors? Thorax. 2010;65(9):815-8.

95. Burudpakdee C, Seetasith A, Dunne P, et al. A realworld study of 30-day exacerbation outcomes in chronic obstructive pulmonary disease (COPD) patients managed with Aerobika OPEP. Pulm Ther. 2017;3:161-71.

96. Burudpakdee C, Near AM, Huang H, et al. A realworld evidence study assessing the impact of adding the Aerobika oscillating positive expiratory pressure device to standard of care upon healthcare resource utilization and costs in post-operative patients. Pulm Ther. 2018;4:87-101.

97. AARC Clinical Practice Guideline. Incentive spirometry: 2011. Respir Care. 2011;56(10): 1600-14.

98. Tse J, Wada K, Wang Y, et al. Impact of oscillating positive expiratory pressure device use on post-discharge hospitalizations: A retrospective cohort study comparing patients with COPD or chronic bronchitis using the Aerobika ${ }^{\circledR}$ and Acapella ${ }^{\circledR}$ Devices. Int J COPD. 2020;15:2527-38.

99. Thanh NX, Jacobs P, Suggett J, et al. Cost-effectiveness of the Aerobika ${ }^{\circledR}$ oscillating positive expiratory pressure device in the management of chronic obstructive pulmonary disease exacerbations in Canada. Can Respir J. 2019;2019:9176504.

100. Sonnenberg FA, Beck JR. Markov models in medical decision making: a practical guide. Med Decis Making. 1993;13(4):322-39.

101. Sin DD, Tu JV. Inhaled corticosteroids and the risk of mortality and readmission in elderly patients with chronic obstructive pulmonary disease. Am J Respir Crit Care Med. 2001;164:580-4.

102. Boersma WG. Antibiotics in acute exacerbations of COPD: the good, the bad and the ugly. Eur Respir J. 2012;40:1-3.
103. Hill AT, Sullivan AL, Chalmers JD, et al. British Thoracic Society guideline for bronchiectasis in adults. Thorax. 2019;74(Suppl. 1):1-69.

104. Global Initiative for Asthma. Global strategy for asthma management and prevention. 2020 Report. Available at: https://ginasthma.org/reports/ , visited August 52021.

105. Castellani C, Duff AJA, Bell SC, et al. ECFS best practice guidelines: the 2018 revision. J Cystic Fibrosis. 2018;17:153-78.

106. Mogayzel PJ, Naureckas ET, Robinson KA. Cystic fibrosis pulmonary guidelines: chronic medications for maintenance of lung health. Am J Respir Crit Care Med. 2013;187(7):680-9.

107. Bott J, Blumenthal S, Muxton M, et al. Guidelines for the physiotherapy management of the adult, medical, spontaneously breathing patient. Thorax. 2008;64(Suppl. 1):i1-51.

108. Lee H, Kim J, Tagmazyan K. Treatment of stable chronic obstructive pulmonary disease: the GOLD guidelines. Am Fam Phys. 2013;88(10): 655-63.

109. Christensen EF, Nørregaard O, Dahl R. Nebulized terbutaline and positive expiratory pressure in chronic obstructive pulmonary disease. Pneumologie. 1991;45(3):105-9.

110. Mesquita FO, Galindo-Filho VC, Neto JL. Scintigraphic assessment of radio-aerosol pulmonary deposition with the Acapella positive expiratory pressure device and various nebulizer configurations. Respir Care. 2014;59(3):328-33.

111. Berlinski A. In vitro evaluation of positive expiratory pressure devices attached to nebulizers. Respir Care. 2014;59(2):216-22.

112. Mitchell JP, Suggett J, Nagel M. et al. Combining inhalation by a breath-actuated nebulizer with exhalation through an oscillating positive pressure device (OPEP) offers the potential for combined therapy. Drug Delivery to the Lungs-24, Edinburgh, UK, December 2013, 322-5.

113. Copelin D. Implementation of a breath-actuated nebulizer regimen may reduce nosocomial influenza acquired by exposure to fugitive droplet emissions from continuous nebulizers whose droplets produced during exhalation are vented to the environment. Respir Care. 2018;63(Suppl 10): 3016143.

114. Ari A. Practical strategies for a safe and effective delivery of aerosolized medications to patients with COVID-19. Respir Med. 2020;167:105987. 
115. Costella S, Kirchner A, Morton R. et al. Smart oscillating positive expiratory pressure device. 2018; US Patent Application 0008790 A1.

116. López-Campos JL, Gallego EQ, Hernández L. Status of and strategies for improving adherence to COPD treatment. Int J Chron Obstruct Pulm Dis. 2019;14: 1503-15.

117. Daniels T, Goodacre L, Sutton C, et al. Accurate assessment of adherence: self-report and clinician report vs electronic monitoring of nebulizers. Chest. 2011;140(2):425-32.

118. Ni Y, Ding L, Yu Y, et al. Oscillatory positive expiratory pressure treatment in lower respiratory tract infection. Exp Ther Med. 2018;16:3241-8.

119. Rossman CM, Waldes R, Sampson D, et al. Effect of chest physiotherapy on the removal of mucus in patients with cystic fibrosis. Am Rev Respir Dis. 1982;126:131-5.

120. Holtzman MJ, Tyner JW, Kim EY, et al. Acute and chronic airway responses to viral infection: implications for asthma and chronic obstructive pulmonary disease. Proc Am Thorac Soc. 2005;2(2): $132-40$.

121. Burgel PR, Nadel JA. Roles of epidermal growth factor receptor activation in epithelial cell repair and mucin production in airway epithelium. Thorax. 2004;59(11):992-6.

122. Ramos FL, Krahnke JS, Kim V. Clinical issues of mucus accumulation in COPD. Int J COPD. 2014;9: 139-50.

123. Gursli S, Sandvik L, Bakkeheim E, et al. Evaluation of a novel technique in airway clearance therapySpecific Cough Technique (SCT) in cystic fibrosis: a pilot study of a series of N-of-1 randomised controlled trials. SAGE Open Med. 2017;5:1-8.

124. Ciesla ND. Chest physical therapy for patients in the intensive care unit. Phys Ther. 1996;76(6): 609-25.

125. COPD Support. The huff-cough technique. 2021. Available at: https://www.copdsupport.ie/aboutcopd/how-to-manage-with-c-o-p-d/controlledcoughing/cough-technique, visited August 5, 2021. 